IZA DP No. 7001

Movin' on Up: Hierarchical Occupational

Segmentation and Gender Wage Gaps

Dina Shatnawi

Ronald Oaxaca

Michael Ransom

November 2012 


\title{
Movin' on Up: Hierarchical Occupational Segmentation and Gender Wage Gaps
}

\author{
Dina Shatnawi \\ Naval Postgraduate School \\ Ronald Oaxaca \\ University of Arizona \\ and IZA \\ Michael Ransom \\ Brigham Young University \\ and IZA
}

\section{Discussion Paper No. 7001 \\ November 2012}

IZA
P.O. Box 7240
53072 Bonn
Germany

\author{
Phone: +49-228-3894-0 \\ Fax: +49-228-3894-180 \\ E-mail: iza@iza.org
}

\begin{abstract}
Any opinions expressed here are those of the author(s) and not those of IZA. Research published in this series may include views on policy, but the institute itself takes no institutional policy positions. The IZA research network is committed to the IZA Guiding Principles of Research Integrity.
\end{abstract}

The Institute for the Study of Labor (IZA) in Bonn is a local and virtual international research center and a place of communication between science, politics and business. IZA is an independent nonprofit organization supported by Deutsche Post Foundation. The center is associated with the University of Bonn and offers a stimulating research environment through its international network, workshops and conferences, data service, project support, research visits and doctoral program. IZA engages in (i) original and internationally competitive research in all fields of labor economics, (ii) development of policy concepts, and (iii) dissemination of research results and concepts to the interested public.

IZA Discussion Papers often represent preliminary work and are circulated to encourage discussion. Citation of such a paper should account for its provisional character. A revised version may be available directly from the author. 
IZA Discussion Paper No. 7001

November 2012

\section{ABSTRACT \\ Movin' on Up: Hierarchical Occupational Segmentation and Gender Wage Gaps*}

Our study evaluates and extends existing wage decomposition methodologies that seek to measure the contributions of endowments, pure wage discrimination, and job segregation. Of particular interest is the model of hierarchical segregation in Baldwin, Butler, and Johnson (2001). We employ data from a regional supermarket that faced a Title VII class-action lawsuit to examine how standard wage specifications integrated with a model of hierarchical segregation might perform in wage decompositions. Our results show that a common misspecification of the wage structure leads to false inferences about the presence of pure wage discrimination. We demonstrate the generalizability of our methodology using CPS data.

JEL Classification: $\quad J 71$

Keywords: gender discrimination, job segregation, wage decompositions

Corresponding author:

Dina Shatnawi

Graduate School of Business and Public Policy

Naval Postgraduate School

Ingersoll Hall, Room 231

555 Dyer Road

Monterey, CA 93943

USA

E-mail: dshatnaw@nps.edu

\footnotetext{
* We would like to acknowledge the helpful comments by Peter Orazem and other participants at the Midwestern Economic Conference (2008), the Western Economic Conference (2008), the University of Otago, and the University of Canterbury, as well as Price Fishback, Jonah Gelbach, Kei Hirano, Ivan Maryanchyk, Alex Roomets, and Will Ingersoll. We would also like to thank Marjorie Baldwin and Richard Butler for their helpful clarifications on important points. Finally, we gratefully acknowledge Trevor Kollmann's assistance with programming.
} 


\section{INTRODUCTION}

This paper employs a unique data set to evaluate existing methodologies that have been used to estimate the effects of intra-firm job segregation on the gender wage gap. Our paper extends existing methodology to better measure the degree of hierarchical discrimination and its impact on wages. We examine problems that arise from using conventional approaches to wage determination and decomposition. Our approach entails a formal derivation of wage - level decompositions under an alternative model of wage determination.

The vehicle for this evaluation is an examination of occupational segregation that took place within a single firm that faced allegations of gender discrimination in job assignments and promotion. It was alleged that women at this firm were deliberately excluded from higher-paying managerial positions and were thus concentrated in the lower-paying job titles. This practice, known as hierarchical segregation, is a more subtle form of discrimination because favoritism towards one gender is harder to substantiate if both men and women are paid equally within job titles.

This differs from the traditional view of occupational segregation, where women are crowded into what are considered female professions such as nursing and consequently depress wages in these occupations. Our evaluation is assisted by a priori knowledge of the wage structure within the firm, an advantage that is absent from most empirical analyses of wage determination and gender wage gaps. We validate the application of the alternative methodology using CPS data to provide information that generalizes beyond what we know from our sample firm.

While there have been several studies that provide an empirical explanation regarding the effects of segregation on the gender wage gap, e.g. Bayard, Hellerstein, Neu-

mark, and Troske (2003), Bergman (1989), Malkiel and Malkiel (1973), and Sorenson $(1989,1990)$, due to a scarcity of firm-level data, relatively few studies have econo- 
metrically explored intra-firm segregation as a mechanism. Most researchers that do have access to firm-level data use the standard hedonic Mincer human capital wage model and the Oaxaca decomposition to measure the factors that contribute to the gender wage gap by including experience, experience-squared, and job title indicators. The inclusion of job title indicators is problematic because typically there are some occupations with no men and others with no women. This issue of empty cells leads to significant problems in the comparability of standard wage regressions and the gender wage decompositions that rely upon them. Beyond the analysis of any particular firm's wage structure, we observe that in unionized firms the rules for wage setting typically require that individuals in the same job title and seniority step be paid the same wage. In such a setting the standard practices, which do not take these factors into account, lead to misspecification and misinterpretation of the relationship between wages and other factors. Therefore, we utilize insider information about our firm's wage structure to determine the direction of the bias that results from conventional approaches and propose an alternative strategy. We then examine the results obtained from the alternative decomposition under the assumption of no insider knowledge to determine the magnitudes of differences in the segregation effect and other factors.

We take a particular interest in empirically examining and extending the methodology set forth in Baldwin, Butler, and Johnson (2001), henceforth, BBJ. Their model of hierarchical segregation assumes men have a distaste for female supervision where discrimination arises due to men being differentially promoted into higher paying managerial job titles. In comparison with the conventional approach to modeling job segregation by examining discrete job classifications, BBJ's methodology treats the job hierarchy as a continuum. Differences in wages imply a different position in the hierarchy. This feature is useful even when considering changes in seniority within a particular job title in addition to moving up the job ladder. We extend the BBJ 
methodology to accommodate nonlinearities from the assumed wage distribution and include an interaction term that frees the segregation effect from being dependent on factors that contribute to wage discrimination.

We employ data from a regional supermarket that faced a Title VII class-action lawsuit for not providing equal promotion opportunities for its female employees. The wage setting process for our sample firm is fairly representative for a wide variety of firms that faced a class-action lawsuit in the mid 1980's over gender discrimination. The firm was accused of discriminating by not promoting females into managerial positions and by paying female workers lower wages through job title assignments. The hierarchical wage structure of the firm is set by gender-neutral union contracts for hourly wage workers such that overt wage discrimination within unionized job titles is nonexistent. Within each job title wage rates are set according to a seniority step function. The advantage of knowing the true wage structure is that it allows us to independently verify how standard wage specifications coupled with a model of hierarchical segregation might perform in wage decompositions that seek to measure the contributions of endowments, pure wage discrimination, and job segregation.

This class action lawsuit is relevant to more recent discrimination cases such as the ongoing lawsuits against Wal-Mart and Costco in which these companies stand accused of preferential treatment towards men. ${ }^{1}$ Both firms are accused of advancing male employees more quickly than female employees, denying female employees equal job assignment and promotions, and failing to consider females for promotion even after considering similar criteria for males. BBJ provides a means of analyzing intra-firm segregation in this context by developing a model in which discrimination depends more on the positions of males and females in the job hierarchy rather than

\footnotetext{
${ }^{1}$ In 2011 the U.S. Supreme Court ruled that the cases against Wal-Mart and Costco could not go forward as class action lawsuits. Subsequently, more narrowly focused cases against the two retailers have been filed in state courts.
} 
a reluctance to work together. Their model assumes that men exhibit distaste for female supervision and derives a sorting function related to wages that predicts the occupational distribution of men and women across job titles. The BBJ approach imposes strong distributional restrictions and its theoretical predictions cannot be adequately tested with CENSUS/CPS type data. We not only utilize our firm sample to evaluate the model, but we also employ a subset of the March 2011 CPS data to provide information with respect to the bias that results from using a standard wage specification in the absence of knowledge of the true wage structure. This exercises exhibits the generalizability of the knowledge gained from the single firm case.

We test the restrictions of the BBJ model derived from the lognormal and gamma wage distributions and examine the robustness of the BBJ methodology in a setting in which the true wage structure and the outcome of the court case are known. We believe that our regional grocery store chain data are better suited to the task of evaluating the model than industry level data or other firm-level data for several reasons. First, the weakness of using industry level data is that aggregation occurs across hetergeneous employers, wage structures, and job ladders, and the results are not as robust when looking across multiple employers as opposed to a single entity. Second, in any wage decomposition there exists ambiguity over whether segregation is due to voluntary choices stemming from equal constraints or because one group faces discriminatory constraints in the labor market. Given that the case was settled in the women's favor, we resolve this identification issue by assuming that job positioning for some of the women at the firm was discriminatory and involuntary. ${ }^{2}$ Lastly,

\footnotetext{
${ }^{2}$ Some may argue that not all women in the firm would be willing to take on the extra responsibility of the managerial positions even if they were ofered the title, especially those women who cannot commit extra time to the firm because of child-raising responsibilities. However the case was a class-action lawsuit stemming from multiple allegations, and the court eventually ruled that enough women sought these positions and the firm consistently denied women the opportunity to move up the job ladder. Thus, we accept that occupational segregation in this firm stemmed mainly
} 
there is a fundamental wage decomposition problem in estimating the effects of gender differences in the returns to occupational affiliation with respect to the left out reference group (Jones (1983)), Oaxaca and Ransom (1999), Gardeazabal and Ugidos (2004), Gelbach (working paper) and Yun (2005)). While the overall estimated segregation effect is invariant to the choice of the left out occupational dummy variable in the wage decomposition, the contribution of gender differences in occupational wage returns to the gender wage gap is not. We are able to avoid this specific problem using BBJ's approach because one dispenses with the need to specify occupational categories ex-ante since each wage corresponds to a different job position.

The objective of our study is to analyze the sensitivity of the results to commonly used wage distributions and test the restrictions placed on the model to determine: (1) if BBJ's approach accurately models the hierarchical discrimination observed in our data set, (2) explore how standard wage specifications imbedded in a model of hierarchical segregation might perform in wage decompositions that seek to measure the contributions of endowments, pure wage discrimination, and segregation, and (3) in the process, extend the implementation of log wage decompositions in the hierarchical segregation framework to examine wage-level differences between men and women. As a practical matter we accept the necessity for the participants in discrimination lawsuits to understand the magnitude of the wage gaps in terms of the actual dollar units. When implementing decompositions in wage-levels it is important to note that the difference in sample average wages do not generally correspond to the difference in the average of conditional wages. Thus we account for the nonlinearity that arises from the assumed wage distribution and include an interaction term that frees the segregation term in the wage decomposition from dependence on the factors that contribute to wage discrimination. Finally (4) we perform the same exercise using from discriminatory practices and therefore could be expected to largely contribute to the gender wage gap. 
CPS data to provide generalizable results with respect to hierarchical discrimination.

The remainder of the paper proceeds as follows: Section 2 describes the previous literature and criticisms. Section 3 describes our extension of the BBJ methodology and model used for estimation including the derivation of wage-level decompositions in the hierarchical segregation framework and an alternative estimation strategy when encountering convergence issues. Section 4 describes the sample from the grocery store data including summary statistics and preliminary regression results that provide evidence of hierarchical segregation. Section 5 provides empirical results obtained using our extension of the BBJ decomposition in the case of an assumed lognormal wage distribution. We then analyze the advantages of extending the hierarchical segregation model vis-à-vis conventional wage-level decompositions that include job title indicators. Section 6 concludes.

\section{LITERATURE REVIEW}

Hierarchical discrimination or intra-firm segregation closely follows the literature on occupational crowding (Bergman (1989) and Sorensen $(1989,1990)$ ). The traditional theory of occupational crowding assumes that women's job choices are limited to positions that society deems feminine. Thus, women tend to be concentrated in low paying jobs and men are concentrated in high paying jobs. Employers reserve certain positions for men, decreasing the demand for women in non-female dominated occupations. As a result the supply of women increases in occupations considered "women's work" exerting downward pressure on equilibrium wages, where women become undervalued in the labor market. Bayard, Hellerstein, Neumark, and Troske (2003) compliment previous studies on occupational segregation by analyzing a dataset that provides a more nationally representative assessment of the mechanisms affecting the gender wage gap. Their methodology is very similar to Johnson and Solon (1986), Sorensen (1989), and Macpherson and Hirsch (1995) and find that 
women's wages decrease in industries and establishments that have higher proportions of females.

There are few studies that examine intra-firm segregation and even fewer that test econometric models of hierarchical discrimination. Malkiel and Malkiel (1973) is one of the first studies that uses firm level data from a professional organization to examine how "job level" assignment affects the gender wage gap. Malkiel and Malkiel run simple ordinary least squares wage regressions controlling for individual characteristics, actual experience, education, and job level. Their findings, similar to Ransom and Oaxaca (2005), indicate that job level explains most of the variation in wages among men and women. However, the Malkiel and Malkiel study was unable to distinguish between whether women chose to invest in less human capital, resulting in the firm assigning women to lower job levels, or whether the firm was participating in discriminatory practices. They were able to state that the firm compensated men and women equally within each job level. Unfortunately, men and women with the same characteristics did not necessarily receive the same salary since women were generally assigned to the lower salaried positions.

BBJ's firm level theory of hierarchical discrimination is based on the evolution of gender specific occupational structures that have developed over the years (Bergman (1986, 1989), Blau and Ferber (1991), Costa (2000), Fuchs (1988), Goldin (1990), and Macpherson and Hirsch (1995)). Before 1950, these occupational structures were not developed with the intention of accommodating females in higher managerial positions, since it was assumed that women would leave the labor market upon marriage. Polachek $(1981,1987)$ offers a human capital explanation for gender differences in occupational distributions that appeals to the atrophy effects of anticipated intermittent labor force participation. It has been shown that women who anticipate spells of absences from the labor force choose jobs with lower returns. However, Blau and Ferber's (1991) study finds that while professional women expect similar starting 
salaries, they anticipate lower earnings than their male counterparts over the course of their working lives even after controlling for time spent out of the labor market. Because occupational structures have not evolved as fast as the perception of workplace equality between males and females, BBJ hypothesizes that males exhibit distaste for female supervision. In order to compensate for this distaste, males require a wage premium, thus a cost minimizing firm will promote a male candidate over a female candidate or hire solely all women. Consequently, a possible reason why a gender wage gap still exists is because women are not promoted as quickly as men or because women are held to higher promotional standards (Blau and Ferber (1991), Malkiel and Malkiel (1973), and Olson and Becker (1983)).

BBJ decomposes hierarchical discrimination's influence on mean female wages into an occupational effect and a wage effect, where female wages are reduced in order to compensate for the discriminatory employment costs. ${ }^{3}$ They evaluate their model using the 1988 Current Population Survey (CPS) sample of workers in the insurance industry, and estimate the effects of hierarchical discrimination on occupational positioning and wages. However they were not able to evaluate all the predictions of the model because they did not have access to firm level data with appropriate occupational hierarchies. This shortcoming of the data only allowed them to verify that the data were consistent with the hypothesis that the relative number of females declines exponentially as one moves up the job ladder.

\footnotetext{
${ }^{3}$ In the case of our regional grocery store chain, all hourly wage-workers were paid the same union scale regardless of gender. Consequently, it is not possible for males to receive a wage premium had the firm chosen to promote women instead. Interestingly enough, we still do not observe women in higher supervisory positions even among the hourly wage-workers. Union contracts enhance segregation because the employer is restricted from compensating males for hiring female managers.
} 


\section{MODEL}

In this paper we extend the BBJ decomposition to account for non-linearities that arise from the assumed wage distribution as well as include an interaction term that frees the segregation component from being dependent on the factors that contribute to wage discrimination. The BBJ model is motivated by the hypothesis that labor market discrimination against women depends more on the positions of men and women in the job hierarchies as opposed to a desire to avoid working in proximity to one another. Thus, the contribution of their paper is that they are able to identify a segregation term without having to choose ex-ante the number or level of occupational titles. In the empirical implementation, the job titles are considered to be a continuous function of wages in that each wage represents a different position in the hierarchy. When job titles are viewed in this way, one might consider that men have a distaste or resentment from being in a subordinate wage position. The discriminatory pattern is such that even if wages are equalized across the sexes by job title, females are only promoted along the job ladder if their responsibility is limited to exclusively supervising women. Therefore it is reasonable to suppose that hierarchical discrimination reduces the proportion of females relative to the proportion of male workers as one moves up the job ladder. Specifically, BBJ predicts a sorting function with an exponential decline in the relative proportions of female to male workers as one moves up the management hierarchy. ${ }^{4}$ However, we will de-emphasize the role of the exponentially declining sorting function because BBJ's methodology only requires that the sorting function be a negative function of wages. In particular, the form of

\footnotetext{
${ }^{4}$ This is based on simulating bivariate normally distributed investment costs (investment in skill or ability for the worker to become a supervisor or manager). The equilibria are computed for three specifications for both the Leontief and Cobb-Douglas technologies using a grid search method. For all technologies, they reject the alternative of a random distribution of women across the job hierarchy. Their simulation results find the rate of exponential decline to be 0.6.
} 
the sorting function, $g(w)$, will depend on the distributional assumptions placed on male wages. Consequently, the derivation of the sorting function is simplified when assuming a wage distribution from the exponential family.

There are two candidates from the exponential family that are commonly used to model wage distributions; the lognormal and the gamma. Although BBJ confined their empirical analysis to the gamma wage distribution, our analysis will be confined to the lognormal distribution because it is the most common wage distribution in the labor economics literature. ${ }^{5}$ We first derive the conventional decomposition using the standard Mincer wage specification with discrete job titles. Then we briefly review the BBJ methodology using the lognormal distribution and finally proceed with our variation of the decomposition for the lognormal wage distribution.

\subsection{Conventional Decomposition}

One objective of this paper is to compare the conventional decomposition that controls for discrete job titles or occupations to an alternative methodology that treats job titles as a continum of wages. In the conventional decomposition, typically, the male and female wage regressions are estimated separately:

$$
\begin{aligned}
& \ln \left(w_{m i}\right)=x_{m i} \alpha_{m}+J_{o m i} \beta_{o m}+J_{m i} \beta_{m}+\varepsilon_{m i} \\
& \ln \left(w_{f i}\right)=x_{f i} \alpha_{f}+J_{o f i} \beta_{o f}+J_{f i} \beta_{f}+\varepsilon_{f i}
\end{aligned}
$$

where $J_{o}$ is a vector of job title dummy variables in which males and females overlap, $J_{m}$ and $J_{f}$ are gender segregated job title dummy variables for all-male and allfemale job titles, the $\beta^{\prime} s$ are the corresponding vectors of job title coefficients, and $\varepsilon_{j}$ $\sim N\left(0, \sigma_{j}^{2}\right), j=1,2$.

\footnotetext{
${ }^{5}$ See Appendix for our analysis using the gamma wage distribution.
} 
Standard practice with the semi-log model is for the wage decomposition to be calculated in terms of log wages. The conventional log wage decomposition may be expressed by

$$
\begin{aligned}
\overline{\ln \left(w_{m}\right)}-\overline{\ell n\left(w_{f}\right)}= & {\left[\left(\bar{x}_{m}-\bar{x}_{f}\right) \hat{\alpha}_{m}+\left(\bar{J}_{o m}-\bar{J}_{o f}\right) \hat{\beta}_{o m}\right] } \\
& +\left[\bar{x}_{m}\left(\hat{\alpha}_{m}-\hat{\alpha}_{f}\right)+\bar{J}_{o m}\left(\hat{\beta}_{o m}-\hat{\beta}_{o f}\right)\right] \\
& +\left[\left(\bar{x}_{m}-\bar{x}_{f}\right)\left(\hat{\alpha}_{m}-\hat{\alpha}_{f}\right)+\left(\bar{J}_{o m}-\bar{J}_{o f}\right)\left(\hat{\beta}_{o m}-\hat{\beta}_{o f}\right)\right] \\
& +\left[\bar{J}_{m} \hat{\beta}_{m}-\bar{J}_{f} \hat{\beta}_{f}\right]
\end{aligned}
$$

Unfortunately, the presence of non-overlapping job title distributions confounds any attempt at identifying the pure discrimination, job segregation, endowment, and interaction components of the log wage decomposition. For example the first term in brackets on the RHS of eq.(3) cannot unambiguously be identified as the endowment effect because of the arbitrariness of attempting to further decompose the last term in brackets, i.e. $\left[\bar{J}_{m} \hat{\beta}_{m}-\bar{J}_{f} \hat{\beta}_{f}\right]$. In fact because of non-overlapping job titles the term $\left(\bar{J}_{o m}-\bar{J}_{o f}\right) \hat{\beta}_{o m}$ cannot be interpreted unambiguously as the effect of occupational segregation. While the decomposition terms are simplified somewhat in the case in which pure wage discrimination is absent, the fundamental problem of non-overlapping job title distributions remains:

$$
\overline{\ln \left(w_{m}\right)}-\overline{\ln \left(w_{f}\right)}=\left(\bar{x}_{m}-\bar{x}_{f}\right) \hat{\alpha}+\left(\bar{J}_{o m}-\bar{J}_{o f}\right) \hat{\beta}_{o}+\left[\bar{J}_{m} \hat{\beta}_{m}-\bar{J}_{f} \hat{\beta}_{f}\right]
$$

One could subtract the term $\left[\bar{J}_{m} \hat{\beta}_{m}-\bar{J}_{f} \hat{\beta}_{f}\right]$ from both sides of the decompositions given by (3) and (4). Alternatively, one could limit the estimation and decomposition to the sub sample of workers for whom the occupational distributions overlap. Neither of these alternatives is particularly attractive. While our focus here is on wage levels, converting to a wage level decomposition from the conventional log wage model will not change the fundamental problem of non-overlapping job title distributions. 


\subsection{Hierarchical Model-Lognormal Distribution}

In order to identify the effect of segregation on the gender wage gap, one first assumes a wage distribution for males. With homogenous workers, pure wage discrimination is manifest by the female wage within job titles appearing as a constant fraction of the corresponding male wage. We start by specifying the male wage density $f_{m}\left(w_{h}\right)$ corresponding to the log normal distribution where each wage represents a different job title $h$ (for simplicity we suppress the subscript $h$ )

$$
f_{m}(w)=\frac{1}{w \sigma \sqrt{2 \pi}} \exp \left(\frac{-(\ln (w)-\mu)^{2}}{2 \sigma^{2}}\right) .
$$

Restricting the parameters of the wage distribution for females to be proportional to the parameters of the wage distribution for males implies that the wage density for females will come from the same class of distributions as the male wage density. This in turn implies that if the female wage distribution is a conjugate form of the male wage distribution, then the returns on occupational affiliation will be proportional to those of the males. The constant of proportionality is the segregation term, $\gamma$. Thus, given a parametric wage distribution, the sorting function (which determines the occupational distribution of females relative to males) will decline in a monotonic transformation of the wage. Equation (6) shows that if wages are lognormal, then the sorting function will exhibit an exponential decline only because the lognormal is a member of the exponential family:

$$
g(w)=\gamma \cdot \exp \left\{\frac{-\left(\gamma^{2}-1\right) \ln (w)}{2 \sigma^{2}}\left[\ln \left(\frac{w}{\exp \left(\frac{2 \mu}{\gamma+1}\right)}\right)\right]\right\}, \gamma>1
$$

The female wage distribution depends on the discriminatory sorting function and the male wage distribution, thus $f_{f}(w)$ is derived by multiplying $f_{m}(w)$ by $g(w)$ : 


$$
f_{f}(w)=\frac{1}{w\left(\frac{\sigma}{\gamma}\right) \sqrt{2 \pi}} \exp \left[\frac{-\left(\ln (w)-\frac{\mu}{\gamma}\right)^{2}}{2\left(\frac{\sigma}{\gamma}\right)^{2}}\right]
$$

It is evident that hierarchical segregation in this model implies lower wage dispersion for females. Notice that as $\gamma$ approaches 1 in the limit, occupational segregation vanishes and the female wage distribution converges to the male wage distribution. ${ }^{6}$

In the homogeneous worker case BBJ obtain the coefficients of interest by jointly estimating the male and female wage likelihood functions. The mean log wage difference is then decomposed into occupational segregation effects and within-occupational wage differences (discrimination). This methodology dispenses with the need to specify ex ante the number of occupational titles because each wage rate represents a different occupation. Thus, in equations (6), (7), w not only represents a different wage, but also a wage corresponding to a particular job title. This is an alternative method to the original decomposition proposed by Oaxaca (1973) because the assumption of a continuum of occupational categories with a specific wage density function avoids issues in estimating the effects of gender differences in the returns to occupational affiliation with an arbitrary left out reference group (Jones (1983), Oaxaca and Ransom (1999), Gardeazabal and Ugidos (2004), and Yun (2005)).

A problem with the Oaxaca decomposition in its original form is that ambiguity exists over whether between-group differences in occupational distributions can be interpreted as discriminatory effects of occupational segregation or as non-discriminatory differences in labor supply choices. This issue is avoided when BBJ integrate the occupational sorting function into the joint likelihood function. The segregation parameter is identified and is used to estimate the effect of hierarchical discrimination.

\footnotetext{
${ }^{6}$ From the functional form of the sorting function as given in BBJ one can easily verify that the female wage distribution derived from the sorting function is a proper density function.
} 
Additionally, the case for interpreting job positioning as discriminatory and involuntary in our data is based on the fact that the women brought suit and the class-action lawsuit was settled in the women's favor. In section 4, we will discuss the data and its origins in more detail.

As alluded to above, within the BBJ framework two cases arise in the treatment of the gender wage decomposition. The first is a special case in which it is assumed that wages within each job title are fixed and workers are homogenous. Since there are no differences in characteristics other than sex, and wages are equalized within each job category, the human capital and wage discrimination effects are eliminated and the decomposition reduces to a segregation term. Thus, the decomposition attributes all differences in wages to occupational segregation. The expected log wage difference between males and females is given by

$$
E\left[\ln \left(w_{m}\right)\right]-E\left[\ln \left(w_{f}\right)\right]=\mu\left(\frac{\gamma-1}{\gamma}\right)
$$

where $E\left[\ln \left(w_{m}\right)\right]=\mu_{m}=\mu$ is the expected log wage for males and $\gamma$ is the segregation coefficient. It is easily verified that the expected log wage for females is given by $E\left[\ln \left(w_{f}\right)\right]=\mu_{f}=\frac{\mu_{m}}{\gamma}=\frac{\mu}{\gamma}$. In terms of variances we have $\operatorname{var}\left[\ln \left(w_{m}\right)\right]=\sigma_{m}^{2}=\sigma^{2}$ and $\operatorname{var}\left[\ln \left(w_{f}\right)\right]=\sigma_{f}^{2}=\left(\frac{\sigma_{m}}{\gamma}\right)^{2}=\left(\frac{\sigma}{\gamma}\right)^{2}$. The model imposes the restriction $\gamma=\frac{\mu_{m}}{\mu_{f}}=\frac{\sigma_{m}}{\sigma_{f}}$. In this simple case, the most efficient estimation would be joint estimation of the parameters $\mu, \gamma$, and $\sigma$ by MLE.

Partly for reasons of comparability across different classes of wage distributions, our interest in this paper focuses on decompositions of wage levels. With the assumption of a $\log$ normal distribution, it follows that $E\left(w_{m}\right)=\exp \left(\mu+\frac{\sigma^{2}}{2}\right)$ and $E\left(w_{f}\right)=$ $\exp \left(\frac{\mu}{\gamma}+\frac{\sigma^{2}}{2 \gamma^{2}}\right)$. Accordingly, the decomposition in this special case can be expressed 
as

$$
E\left(w_{m}\right)-E\left(w_{f}\right)=\exp \left(\mu+\frac{\sigma^{2}}{2}\right)-\exp \left(\frac{\mu}{\gamma}+\frac{\sigma^{2}}{2 \gamma^{2}}\right) .
$$

It is important to recognize that the decomposition described by (9) in general does not correspond to the difference in the sample average of individual conditional mean wages. Consequently, we further extend the BBJ decomposition to account for the non-linear nature of the lognormal distribution (Oaxaca and Ransom (2003) and Sarnikar, Sorensen, and Oaxaca (2007)). In order to operationalize the decomposition, we replace the parameters by their MLE's:

$$
\begin{aligned}
& \bar{w}_{m}=\exp \left(\hat{\mu}+0.5 \hat{\sigma}^{2}+\hat{\theta}_{m}\right) \\
& \bar{w}_{f}=\exp \left(\frac{\hat{\mu}}{\hat{\gamma}}+0.5 \frac{\hat{\sigma}^{2}}{\hat{\gamma}^{2}}+\widehat{\theta}_{f}\right)
\end{aligned}
$$

where $\widehat{\theta}_{m}$ and $\widehat{\theta}_{f}$ are remainder terms that equate the means of the predicted wages for males and females to their sample means, i.e.

$$
\begin{gathered}
\widehat{\theta}_{m}=\ln \left(\bar{w}_{m}\right)-\left(\hat{\mu}+0.5 \hat{\sigma}^{2}\right) \\
\widehat{\theta}_{f}=\ln \left(\bar{w}_{f}\right)-\left(\frac{\hat{\mu}}{\hat{\gamma}}+0.5 \frac{\hat{\sigma}^{2}}{\hat{\gamma}^{2}}\right)
\end{gathered}
$$

The empirical analog of the wage decomposition in (9) is given by

$$
\begin{aligned}
\bar{w}_{m}-\bar{w}_{f}= & {\left[\exp \left(\hat{\theta}_{m}\right)\right]\left[\exp \left(\hat{\mu}+0.5 \hat{\sigma}^{2}\right)-\exp \left(\frac{\hat{\mu}}{\hat{\gamma}}+0.5 \frac{\hat{\sigma}^{2}}{\hat{\gamma}^{2}}\right)\right] } \\
& +\exp \left(\frac{\hat{\mu}}{\hat{\gamma}}+0.5 \frac{\hat{\sigma}^{2}}{\hat{\gamma}^{2}}\right)\left[\exp \left(\widehat{\theta}_{m}\right)-\exp \left(\widehat{\theta}_{f}\right)\right] .
\end{aligned}
$$

The first term in (12) is an estimate of the gender wage gap attributable to segregation, and the second term captures the sample mean wage difference due to gender differences in the deviation between sample mean wages and predicted mean wages. 
The second case considered by BBJ introduces worker heterogeneity and allows wages to vary within each job title according to personal characteristics. The density functions are expressed as

$$
f_{m}(w)=\frac{1}{w \sigma \sqrt{2 \pi}} \exp \left(\frac{-\left(\ln (w)-\mu_{m}\right)^{2}}{2 \sigma^{2}}\right)
$$

and

$$
f_{f}(w)=\frac{1}{w\left(\frac{\sigma}{\gamma}\right) \sqrt{2 \pi}} \exp \left[\frac{-\left(\ln (w)-\mu_{f}\right)^{2}}{2\left(\frac{\sigma}{\gamma}\right)^{2}}\right]
$$

Conditioning on worker characteristics $(x)$ introduces additional parameters $(\alpha)$, where $\mu_{m}=x_{m} \alpha_{m}, \mu_{f}=x_{f} \alpha_{f}^{*}$, and $\alpha_{f}^{*}=\frac{\alpha_{f}}{\gamma}$.

With worker heterogeneity the presence of wage discrimination implies that female wage rates within each job title are a fraction $(\phi)$ of the wage rates the females would face if their characteristics were valued at the male returns:

$$
\phi=\exp \left[\left(x_{f}\right)\left(\alpha_{f}-\alpha_{m}\right)\right]
$$

or in terms of logs we have the familiar wage discrimination coefficient:

$$
\ln (\phi)=-x_{f}\left(\alpha_{m}-\alpha_{f}\right)=x_{f}\left(\alpha_{f}-\alpha_{m}\right)
$$

Clearly in the absence of wage discrimination, $\alpha_{m}-\alpha_{f}=0 \Rightarrow \phi=1$.

The female wage density (14) implies

$$
\begin{aligned}
E\left[\ln \left(w_{f}\right)\right] & =\mu_{f} \\
& =x_{f} \alpha_{f}^{*} \\
& =\frac{x_{f} \alpha_{f}}{\gamma}
\end{aligned}
$$


If we substitute $x_{f} \alpha_{f}=x_{f} \alpha_{m}+\ell n(\phi)$ obtained from (16) into (17), worker heterogeneity, wage discrimination, and segregation imply

$$
E\left[\ln \left(w_{f}\right)\right]=\frac{x_{f} \alpha_{m}}{\gamma}+\frac{\ell n(\phi)}{\gamma} .
$$

With worker heterogeneity and conditioning on sample mean characteristics $(\bar{x})$, the expected (conditional) log wage decomposition can be written as

$$
E\left[\ln \left(w_{m} \mid \bar{x}_{m}\right)\right]-E\left[\ln \left(w_{f} \mid \bar{x}_{f}\right)\right]=\left(\bar{x}_{m}-\bar{x}_{f}\right) \alpha_{m}+\bar{x}_{f}\left(\alpha_{m}-\alpha_{f}\right)+\bar{x}_{f} \alpha_{f}\left(\frac{\gamma-1}{\gamma}\right) .
$$

The first two terms in (19) correspond to the Oaxaca decomposition where the wage difference is attributed to differences in individual characteristics and differences attributed to discrimination. The last term corresponds to the log wage difference attributed to occupational segregation.

Given that the male wage structure is the nondiscriminatory norm, an issue that could be raised with decomposition (19) is that the discrimination term $\bar{x}_{f}\left(\alpha_{m}-\alpha_{f}\right)$ is based on the characteristics of the female sample, and the segregation measure $\bar{x}_{f} \alpha_{f}\left(\frac{\gamma-1}{\gamma}\right)$ depends both on the female sample characteristics and the effects of wage discrimination for $\alpha_{f} \neq \alpha_{m}$. This issue is an example of the problem of constructing counterfactuals when there is not complete overlap in the distributions of characteristics for two populations being compared. One way to address this concern is to employ a standard approach in decompositions that introduces an interaction term between coefficient and characteristics differences. Extending this approach to the BBJ decomposition yields the following decomposition:

$$
\begin{aligned}
E\left[\ln \left(w_{m} \mid \bar{x}_{m}\right)\right]-E\left[\ln \left(w_{f} \mid \bar{x}_{f}\right)\right]= & \left(\bar{x}_{m}-\bar{x}_{f}\right) \alpha_{m}+\bar{x}_{m}\left(\alpha_{m}-\alpha_{f}\right)+\bar{x}_{m} \alpha_{m}\left(\frac{\gamma-1}{\gamma}\right) \\
& -\left[\left(\bar{x}_{m}-\bar{x}_{f}\right)\left(\alpha_{m}-\alpha_{f}\right)\right. \\
& \left.+\left(\bar{x}_{m} \alpha_{m}-\bar{x}_{f} \alpha_{f}\right)\left(\frac{\gamma-1}{\gamma}\right)\right] .
\end{aligned}
$$


The discrimination term $\bar{x}_{m}\left(\alpha_{m}-\alpha_{f}\right)$ and the segregation measure $\bar{x}_{m} \alpha_{m}\left(\frac{\gamma-1}{\gamma}\right)^{7}$ are freed of their dependence on the characteristics of the female sample and on wage discrimination, respectively. Sorting out the decomposition in this manner generates an interaction term $-\left[\left(\bar{x}_{m}-\bar{x}_{f}\right)\left(\alpha_{m}-\alpha_{f}\right)+\left(\bar{x}_{m} \alpha_{m}-\bar{x}_{f} \alpha_{f}\right)\left(\frac{\gamma-1}{\gamma}\right)\right]$ composed of the interactions between endowment differences, discrimination, and segregation.

In the case of wage level decompositions, the situation is a bit more complicated. For simplicity we condition on the true parameter values to obtain the expected wage gap between a representative male and a representative female at the respective sample mean characteristics:

$$
E\left(w_{m} \mid \bar{x}_{m}\right)-E\left(w_{f} \mid \bar{x}_{f}\right)=\exp \left(\bar{x}_{m} \alpha_{m}+\frac{\sigma^{2}}{2}\right)-\exp \left(\frac{\bar{x}_{f} \alpha_{f}}{\gamma}+\frac{\sigma^{2}}{2 \gamma^{2}}\right) .
$$

After some algebraic manipulation we extend the BBJ model to obtain a wage decomposition for this case:

$$
\begin{aligned}
E\left(w_{m} \mid \bar{x}_{m}\right)-E\left(w_{f} \mid \bar{x}_{f}\right)= & {\left[\exp \left(\frac{\sigma^{2}}{2}\right)\right]\left[\exp \left(\bar{x}_{m} \alpha_{m}\right)-\exp \left(\bar{x}_{f} \alpha_{m}\right)\right] } \\
& +\left[\exp \left(\frac{\sigma^{2}}{2}\right)\right]\left[\exp \left(\bar{x}_{m} \alpha_{m}\right)-\exp \left(\bar{x}_{m} \alpha_{f}\right)\right] \\
& +\exp \left(\frac{\sigma^{2}}{2}\right)\left[\exp \left(\bar{x}_{m} \alpha_{m}\right)-\exp \left(\frac{\bar{x}_{m} \alpha_{m}}{\gamma}\right)\right] \\
& +\left\{\operatorname { e x p } ( \frac { \sigma ^ { 2 } } { 2 } ) \left[\exp \bar{x}_{f} \alpha_{m}-2 \exp \left(\bar{x}_{m} \alpha_{m}\right)\right.\right. \\
& \left.+\exp \left(\bar{x}_{m} \alpha_{f}\right)+\exp \left(\frac{\bar{x}_{m} \alpha_{m}}{\gamma}\right)\right] \\
& \left.-\exp \left(\frac{\bar{x}_{f} \alpha_{f}}{\gamma}+\frac{\sigma^{2}}{2 \gamma^{2}}\right)\right\}
\end{aligned}
$$

where the first three terms in (21) correspond to the effects of the wage gap attributed to individual characteristics, wage discrimination, and segregation, respectively. The

\footnotetext{
${ }^{7}$ This segregation measure corresponds exactly to the measure used in BBJ (2001, p.104) for the lognormal distribution.
} 
fourth term measures the interactions between differences in characteristics, discrimination, and segregation.

Since the decomposition described by (21) is evaluated at the sample mean characteristics, we again have to take account of the fact that wage level decompositions based on the log normal do not in general correspond to the difference in the average of individual conditional mean wages. Moreover, the true parameter values have to be replaced with estimates. Consequently, our extension of the BBJ decomposition in this case begins with expressions for estimated means of the wage decomposition components. These definitions are summarized below:

$$
\begin{aligned}
\bar{w}_{m}=N_{m}^{-1} \sum_{i=1}^{N_{m}} \hat{w}_{m_{i}}, & \hat{w}_{m_{i}}=\exp \left(x_{m_{i}} \hat{\alpha}_{m}+\frac{\hat{\sigma}^{2}}{2}+\hat{\theta}_{m}\right) \\
\bar{w}_{f}=N_{f}^{-1} \sum_{i=1}^{N_{f}} \hat{w}_{f_{i}}, & \hat{w}_{f_{i}}=\exp \left(\frac{x_{f_{i}} \hat{\alpha}_{f}}{\hat{\gamma}}+\frac{\hat{\sigma}^{2}}{2 \hat{\gamma}^{2}}+\hat{\theta}_{f}\right) \\
\bar{w}_{f m}=N_{f}^{-1} \sum_{i=1}^{N_{f}} \hat{w}_{f m_{i}}, & \hat{w}_{f m_{i}}=\exp \left(x_{f_{i}} \hat{\alpha}_{m}+\frac{\hat{\sigma}^{2}}{2}+\hat{\theta}_{m}\right) \\
\bar{w}_{m f}=N_{m}^{-1} \sum_{i=1}^{N_{m}} \hat{w}_{m f_{i}}, & \hat{w}_{m f_{i}}=\exp \left(x_{m_{i}} \hat{\alpha}_{f}+\frac{\hat{\sigma}^{2}}{2}+\hat{\theta}_{m}\right) \\
\bar{w}_{\gamma m}=N_{m}^{-1} \sum_{i=1}^{N_{m}} \hat{w}_{\gamma m_{i}}, & \hat{w}_{\gamma m_{i}}=\exp \left(\frac{x_{m_{i}} \hat{\alpha}_{m}}{\hat{\gamma}}+\frac{\hat{\sigma}^{2}}{2 \hat{\gamma}^{2}}+\hat{\theta}_{m}\right)
\end{aligned}
$$

where $\widehat{\theta}_{m}$ and $\widehat{\theta}_{f}$ are remainder terms that equate the means of the predicted wages for males and females to their sample means, i.e.

$$
\begin{gathered}
\widehat{\theta}_{m}=\ln \left(N_{m} \bar{w}_{m}\right)-\ln \left\{\sum_{i}^{N_{m}}\left[\exp \left(x_{m i} \widehat{\alpha}_{m}+\frac{\hat{\sigma}^{2}}{2}\right)\right]\right\} \\
\widehat{\theta}_{f}=\ln \left(N_{f} \bar{w}_{f}\right)-\ln \left\{\sum_{i}^{N_{f}}\left[\exp \left(\frac{x_{f i} \widehat{\alpha}_{f}}{\hat{\gamma}}+\frac{\hat{\sigma}^{2}}{2 \hat{\gamma}^{2}}\right)\right]\right\} .
\end{gathered}
$$

The full decomposition of observed sample mean wages can be expressed as 


$$
\begin{aligned}
\bar{w}_{m}-\bar{w}_{f}= & \left(\bar{w}_{m}-\bar{w}_{f m}\right)+\left(\bar{w}_{m}-\bar{w}_{m f}\right)+\left(\bar{w}_{m}-\bar{w}_{\gamma m}\right) \\
& +\left[1-\exp \left(\hat{\theta}_{f}-\hat{\theta}_{m}\right)\right] \bar{w}_{m} \\
& +\left\{\bar{w}_{f m}+\bar{w}_{m f}+\bar{w}_{\gamma m}-\bar{w}_{f}-\left[3-\exp \left(\hat{\theta}_{f}-\hat{\theta}_{m}\right)\right] \bar{w}_{m}\right\} .
\end{aligned}
$$

The first three terms in (24) are respectively the empirical estimates of the gender wage gap attributable to individual characteristics, wage discrimination, and segregation. The fourth term captures the sample mean wage difference due to gender differences in the deviation between sample mean wages and predicted mean wages, while the fifth term residually reflects the interaction effects between characteristics, discrimination, segregation, and differences in actual and predicted sample means. With the exception of the residual term, all of the decomposition terms are constructed with reference to the male sample. In the absence of wage discrimination, $\bar{w}_{m}=\bar{w}_{m f}$ and the decomposition simplifies somewhat:

$$
\begin{aligned}
& \bar{w}_{m}-\bar{w}_{f}=\left(\bar{w}_{m}-\bar{w}_{f m}\right)+\left(\bar{w}_{m}-\bar{w}_{\gamma m}\right)+\left[1-\exp \left(\hat{\theta}_{f}-\hat{\theta}_{m}\right)\right] \bar{w}_{m} \\
&+\left\{\bar{w}_{f m}+\bar{w}_{\gamma m}-\bar{w}_{f}-\left[2-\exp \left(\hat{\theta}_{f}-\hat{\theta}_{m}\right)\right] \bar{w}_{m}\right\}
\end{aligned}
$$

Our treatment of the log normal version of the BBJ hierarchical segregation model reveals that an important difference between the hierarchical model and the conventional approach to wage level decomposition is that the former does not explicitly control for job titles. Rather, the hierarchical model identifies the effects of job segregation through a parameter $(\gamma)$ estimated on the basis of treating the job hierarchy as a continuum in wage rates. By the same token the conventional wage level decomposition has difficulty in identifying the wage gap effects of job title segregation. Furthermore, the BBJ approach finesses the problem of non-overlapping occupational/job title distributions between men and women by treating job titles as a continuum. In the case of the conventional model, the decompositions shown in 
(3) and (4) are ambiguous in the presence of the empty cell problem that arises when the occupational categories in $J_{o m}$ and $J_{o f}$ are not identical.

\section{DATA}

The data used for our analysis come from a Title VII class action lawsuit brought against a large grocery retailer that faced the same allegations of discriminatory employment practices as Wal-Mart and Costco face today. The firm was found guilty of discrimination in 1984, and negotiated a settlement that required payment of "back pay" as well as the implementation of affirmative action policies for promotion and job assignment. The data span the years 1978-1986. Although the affirmative action policies were not implemented prior to the year-end of 1986, Ransom and Oaxaca (2005) find evidence that the employer was already taking remedial action after the filing of the lawsuit in 1982. Within this time frame we are able to observe the changes in the distribution of male and female job assignments and promotion for retail workers only, as we do not have data for non-retail workers such as accoun-

tants, truck drivers, and janitors. Further information on the data set including characteristics of the firm and details on the union contracts can be found in Ransom and Oaxaca (2005).

This data set can be used to evaluate the Hierarchical Theory of discrimination because it meets the criteria set forth in BBJ: a single employer with a relatively homogeneous group of employees who vary in pay, job titles, and seniority within the firm. Each store in the chain had sixteen job titles, five of which were management level. Examining the raw data provides preliminary evidence that although the union contracts were gender neutral, a large wage differential arose because of occupational segregation. Women received different job assignments than men with similar characteristics. Most of the following details on the data, relevant to this research question, are reproduced from the data section in Ransom and Oaxaca (2005). 
The majority of the employees received hourly wages and worked as food clerks, whereas those in the higher managerial levels received a set salary. Among the hourly wage workers, union contracts guaranteed that wage differences were nonexistent within job titles among men and women with the same seniority; however, the employer had full control over job allocation and whom to hire. The contract only required that the most senior employee be considered for a higher position. ${ }^{8}$ Differences within a particular position reflect differences in seniority, however an individual with high seniority as a food clerk will not receive a higher wage than a manager with a similar seniority level.

The hierarchical structure of the firm is reproduced from Ransom and Oaxaca (2005) in Figure 1. There were four departments in each store: meat, produce, grocery, and variety (non-foods). In addition to the three salaried management positions of Store Manager, Assistant Manager, and Relief Manager, within the meat and produce departments the non-salaried management positions of Meat Manager and Produce Manager were available. The night crew chief supervised stocking of the store during the night for which they received a wage premium and is considered a non-salaried management position.

For the purposes of this study, we chose the year 1981 to evaluate the hierarchical model. The year 1981 was selected because it was prior to the lawsuit, thus the filing of the lawsuit had not yet influenced the behavior of the firm. Summary statistics as of December 1981 for each job title are provided in Table 1. Our data set comprises 786 female and 1,182 male retail employees. These are individuals who were present as of 1981 and had positive earnings. Average characteristics of workers such as age and seniority are included as well as hourly wages for non-salaried workers. Average annual earnings include bonuses paid to managerial employees, and are measured for

\footnotetext{
${ }^{8}$ For more information on the specifics of the labor union contracts see Ransom and Oaxaca (2005).
} 
the end of 1981. The raw numbers show that courtesy clerks earned significantly less than any other position. The high turnover rate for courtesy clerks is also apparent, as they were relatively younger than other employees assigned to other positions and their average seniority was a little less than a year. Interestingly, the average hourly female worker was paid relatively close to or higher than the average hourly male worker in a number of job titles, reflecting the higher average seniority of women within these job titles. Thus a natural question to ask is: why were the average earnings for females less than the average earnings for males? A plausible answer is that women may have been working fewer hours. Part of the lawsuit claims that women were consistently denied the opportunity to work longer hours. ${ }^{9}$

The distribution of men and women across job titles was relatively segregated. Most employees in the store worked as food clerks, a job which required little previous skill or education and was predominately filled by females. The distribution of the store-level and department management positions was disproportionately male. Prior to the filing of the lawsuit, the firm had never employed a female in the store manager position, as seen in Table 2 which describes the distribution of men and women across the job hierarchy as of 1981. The hierarchical categories reported in the table correspond to the wage hierarchies within the firm. Only 0.38 percent of women were in the second, third, and fourth highest occupational rungs. This is particularly interesting because there were no females holding the title of produce manager or meat manager, and 48 men were holding the night manager position compared to 3 women. Women are found to be disproportionately represented in the lowest occupational titles compared to men, and 80 percent of women were found in the second lowest

\footnotetext{
${ }^{9}$ Ransom and Oaxaca (2005) indicate that the percentage of part-time to full-time employees grew at roughly the same rate for males and females, though the distribution was consistently unequal, with 86 percent of women compared to 69 percent of men being part-time employees at the end of the period.
} 
rung. The last column in Table 2 reports the ratio of the fraction of women in each occupational grouping to the fraction of men. Consistent with BBJ expectations, the ratio declines as one moves up the occupational hierarchy. This table alone dramatically reveals the hierarchical character of employment segmentation within the firm.

It is instructive to examine regressions of the logarithm of hourly wages on age, seniority, and job title dummies. Because store manager, assistant manager, and relief manager are salaried, non-union positions, we create an hourly wage variable that is intended to capture the wage differences associated with being assigned to one of the three highest positions. ${ }^{10}$ The hourly wage for the salaried positions is imputed by assuming that the hourly wage for the lowest salaried position is the same as the highest hourly wage for the hourly wage earners. Thus $W_{I I I}$ is defined as the hourly wage for relief managers. The hourly wage for the assistant manager, $W_{I I}$, is defined as $W_{I I}=\frac{E_{I I}}{E_{I I I}} \cdot W_{I I I}$, where $E_{I I}$ and $E_{I I I}$ are the annual earnings for assistant manager and relief manager respectively. Finally, the hourly wage for store manager is defined as $W_{I}=\frac{E_{I}}{E_{I I I}} \cdot W_{I I I}$, where $E_{I}$ is the annual earnings for the store manager position. This insures that we preserve the ranking of wages to positions, implying the hourly wage for store manager is greater than the hourly wage for assistant manager, and in turn larger than the relief manger's hourly wage. While the salaries for the three highest management positions were not based on a union scale, we assume on average that hourly wages in these positions are proportional to each other.

\footnotetext{
${ }^{10}$ We have estimated similar regressions using log earnings rather than our imputed hourly wage; however the results are not as informative since annual earnings do not accurately control for differences in hours worked. We have these results upon request. Unfortunately, we do not have access to actual hours worked. It is plausible that women in this firm were earning less than men on average because they were not working as many hours, ceteris paribus, but we do know from the lawsuit that women sought to work longer hours and were denied them.
} 
Results presented in Table 3 provide preliminary evidence that occupational segregation plays a major role in wage determination within the firm. Specification I shows that women's hourly earnings were 4.4 percent less than men on average. This difference in earnings can be attributed to differences in promotion to higher positions or into full-time positions. It is important to note that it is possible that total earnings may include extra-curricular activities at the firm, such as overtime or bonuses, which may contribute to higher hourly earnings differences between men and women, especially if they were more likely to be offered to males. Unfortunately, the data we observe for hourly wage workers are the straight-time hourly wages.

Specification II shows that after controlling for human capital differences in seniority and age, the wage gap increases from 4.4 percent to 13.4 percent. Furthermore, in specification III we control for job assignment by including indicators for the job title of the employee. Once we allow for different job assignments, the gender wage gap decreases to about 6.7 percent. Interestingly, only including job titles in the regression, shown in specification IV, results in a wage gap of approximately 2 percent. About 83 percent of the variation in earnings can be attributed to job title alone. Ransom and Oaxaca (2005) run a similar regression for non-management hourly wage workers using the logarithm of hourly wages as a dependent variable and find that 95 percent of the variation in wages is attributed to occupational title for the wage workers. Thus, gender differences in pay can mostly be explained by job assignment or firm level segregation. ${ }^{11}$

\footnotetext{
${ }^{11}$ We lack information on the number of hours salaried employees worked. We replicate the regressions using the logarithm of wages presented in Table 5 in Ransom and Oaxaca (2005) with the 1981 data and find the same results: women's wages were higher than men on average. This difference reflects the higher seniority and age of women. However, after controlling for differences in seniority and age, women's wages were actually less than men. Furthermore, once occupational controls are included, over 90 percent of the variation in wages could be explained by job title alone (job titles excluded salaried positions).
} 


\section{MODEL RESULTS}

This section provides the MLE results corresponding to the hierarchical model. We begin by examining the case where workers are homogenous and then allow for wages to vary within each job title by introducing worker heterogeneity. Recall that the union contracts did specify seniority gradients within a particular job title and required that the most senior employee be considered for a higher position. Thus, we include age, age squared, seniority, and seniority squared and estimate the model via maximum likelihood.

In the absence of specific information about the wage setting process within firms, the Mincerian quadratic in age and tenure specification is commonly used in both market and firm level settings. Age might reflect general or pre-firm work experience and seniority captures firm specific experience. In reality there are seniority wage caps within firms and specific job titles. Our firm is no exception. Therefore, we are in a unique position to evaluate the standard specification in a setting in which the wage structure is known for the unionized workers, though not for managerial workers.

Given that our firm employed gender neutral union contracts, we only report the coefficients from the restricted model in the absence of pure wage discrimination. Accordingly, this restriction on the model's parameters eliminates the (wage) discrimination component from the wage decomposition. Below we compare the conventional decomposition results to those obtained from the hierarchical decomposition and thereby test the restrictions imposed by the BBJ model. Furthermore, we apply the hierarchical model to the March 2011 CPS data in an effort to generalize the potential bias that may occur in the absence of knowledge of the wage structure. 


\subsection{Decompositions}

We begin the analysis by assuming worker homogeneity and the absence of pure wage discrimination. The BBJ inspired gender wage decomposition assuming worker homogeneity entails estimating the lognormal distribution for males and females jointly via MLE. This specification appears reasonable given that our sample is relatively homogenous and that the union contracts guaranteed the same starting wage regardless of gender. The coefficient estimates as well as the decomposition results associated with equation (12) are reported in Table 4. Our findings indicate that the distribution of males and females is not equalized across job titles given that the coefficient of segregation, $\gamma$, is greater than 1 . We can easily reject the hypothesis that $\gamma \leq 1$ against the alternative $\gamma>1$. The theoretical implications of this decomposition imply that any difference in mean earnings will be entirely attributed to occupational segregation. In our case, most of the difference will be attributed to hierarchical segregation as we adjust for differences between the conditional mean and sample mean. The decomposition results indicate that 70.8 cents of the 63.3 cent gender wage gap is due to segregation and the remaining -4.5 cents equates the sample means to the predicted conditional means.

While the homogeneity assumption appears reasonable, we know that the union contracts specified that employees with higher seniority be paid a wage premium within a particular job title and required that the most senior employee be considered for openings in higher positions. Thus, we move to an alternate specification that allows wages to vary within job titles by incorporating age, age-squared, seniority, and seniority-squared into the likelihood function.

The classic Mincer human capital wage model specification generally yields very plausible results for heterogenous data and is standard in the labor literature when the institutional details of the firm's wage setting process are unknown. However, 
we are in a unique position where we actually know the wage structure of the firm. Hourly wages for workers within each job title are set according to a gender neutral union wage scale and therefore any within job title wage variation is entirely due to differences in seniority. In fact the wage structure for our firm can be described by seniority step functions within each job title for the hourly wage positions. In this setting, overt wage discrimination within job titles is nonexistent. Theoretically, the entire wage gap should be attributed to some combination of human capital differences and hierarchical segregation. Although the Mincer specification does not literally correspond to the union wage scale faced by our firm, we adopt this specification as an approximation and examine its properties in a specific institutional setting in which it is assumed that the researcher at least knows that pure wage discrimination is absent. Accordingly, in the likelihood function we constrain the returns on seniority and on age to be the same for men and women. ${ }^{12}$ The decomposition results in the absence of a pure wage discrimination component are calculated according to equation $(25)$.

The coefficient estimates and the decomposition results for the heterogeneous case in the absence of pure wage discrimination are reported in Table 5. As in the homogenous case, $\gamma$ (the coefficient of segregation) exceeds 1 . Again we can easily reject the hypothesis that $\gamma \leq 1$ against the alternative $\gamma>1$, which establishes that gender segregation exists within the firm and disadvantages women. Not surprisingly, the highest percentage of the gender wage gap is attributed to hierarchical segregation, where 1.40 dollars of the 66 cent wage gap is due to women being excluded from

\footnotetext{
${ }^{12}$ The payroll data provides an opportunity not unlike a natural experiment where we can compare the decomposition results obtained assuming that the wage structure of the firm is unknown to the decomposition results where we utilize insider knowledge. This will shed light on the specification biases that can arise when the institutional details are unknown, which is unfortunately the case for most researchers.
} 
higher paying job titles. Recall that the firm was advised to promote employees with higher seniority into the salaried managerial positions. While women had higher seniority on average, the firm never employed a female store manager prior to the lawsuit. This is established in the decomposition, where approximately -94.05 cents of the gender wage gap is attributed to worker characteristics. The negative sign implies that women have the advantage in human capital accumulation, thus were more qualified for promotion. This is consistent with BBJ prediction that women would have more human capital than the men because women have higher cost hurdles that have to be overcome by more human capital investment. Given this result we would expect to see women in higher positions in the absence of segregation. The remaining wage difference is accounted for by the statistical correction factor, which adjusts for the difference in predicted average wages and sample mean wages, and the interaction effect.

One must exercise caution when deciding whether to implement the decomposition under the homogenous worker assumption or under the assumption of worker heterogeneity. The researcher can easily misspecify and misinterpret the results of the decomposition when the details of the firm are unknown. This is apparent when comparing results from Table 4 and 5 where we find the decomposition segregation effect under the assumption of heterogenous workers to nearly double from the prior case. Nonetheless the BBJ inspired model seems to accurately capture hierarchical segregation as the dominant factor contributing to the gender wage gap. ${ }^{13}$

\footnotetext{
${ }^{13}$ If one were to assume that none of the institutional details about the wage structure of the firm are known, then presumably one would follow BBJ and jointly estimate the segregation parameter $\gamma$ and the separate returns on the Mincer variables for men and women. In examining this case we encountered convergence issues that lead us to estimate the male and female log wage models separately and infer the value of $\gamma=\frac{\sigma_{m}}{\sigma_{f}}$. The resulting decomposition took the form of equation (24) and yielded a human capital accumulation effect, a wage discrimination effect, and a hierarchical segregation effect. This standard specification coupled with a model of hierarchical segregation
} 
The presence of non-overlapping job titles precludes a meaningful comparison between the BBJ inspired decomposition and a conventional decomposition. The BBJ approach finesses the issue of non-overlapping job titles and is able to identify the human capital effect apart from the segregation effect, which is not the case when using the conventional wage-level decomposition. To facilitate some empirical comparison between the BBJ inspired model and the conventional model, we are able to take into consideration the wage structure of the firm by constraining the parameters in the conventional log wage equations to be the same for males and females. ${ }^{14}$ Our version of the conventional log wage specification includes 13 job positions in addition to the human capital variables. The estimated conventional log wage equation is reported in Table 6.

A comparison between Tables 5 and 6 reveals that the occupational dummy variables greatly attenuate the estimated wage effects of age and tenure compared with the hierarchical segregation model. Clearly, much of the estimated returns to age and tenure are masked by the job title indicator variables. These results reinforce the advantages of using the BBJ inspired decompositions over the conventional decomposition.

\subsection{Applying Hierarchical Model to CPS Data}

Finally, we validate our methodological contribution by applying the hierarchical model to CPS data, which is commonly used by researchers in labor market analysis. grossly misrepresented the actual wage structure and implied wage discrimination against men where pure wage discrimination should not exist at all.

${ }^{14}$ Constraining the parameters in the conventional log wage equations to be the same for males and females will result in a simple case of groupwise heteroskedasticity because the error variances are different between men and women. Indeed the hierarchical segregation model predicts groupwise heteroscedasticity. Thus, we weight the female observations by $1 / \widehat{\sigma}_{f}$ and the male observations by $1 / \widehat{\sigma}_{m}$ and estimate the parameters via FGLS. 
The goal is to determine whether there is a general take-away that extends beyond what we have learned using the grocery store data. In particular, we compare the decomposition results under the assumption that the wage structure is known to the more typical case where the firm's wage structure is unknown. We apply our extension of the BBJ decomposition to a subset of the March 2011 CPS data set. The sample is restricted to individuals who are members of a union or are paid union wages. This allows us to assume that men and women are paid identically for the same position within the hierarchy. Furthermore, we limit the sample to individuals who earn positive wages and are employed in the same industry. This allows us to avoid confounding the effects of occupational/industry segregation and instead estimate hierarchical discrimination. The public administration industry, aggregated to the 2 digit level, was chosen due to the relatively large number of male (171) and female (98) workers.

The mean hourly wages within this sample are 26.54 and 23.67 dollars for males and females respectively resulting in an average wage gap of 2.87 dollars. The wage specification includes education, potential experience, and its square. ${ }^{15}$ Given that we limit our sample to union workers, it is reasonable to assume that overt wage discrimination is nonexistent. Theoretically, we should not observe a discrimination component in the decomposition. However if we do not constrain the model's parameters to be the same between men and women, we obtain results consistent with what we find in our sample firm (see footnote 12), where there is not only a wage discrimination component explaining the gender wage gap, but the magnitudes of each component are implausibly large. ${ }^{16}$

If we move on to the alternate specification where we constrain the returns on

\footnotetext{
${ }^{15}$ We do not include education in our original specification because the workers at the grocery store were homogenous with respect to education and we had their tenure within the firm. This is not necessarily the case for the sample of workers in the CPS.

${ }^{16}$ The decomposition results from this case are available upon request.
} 
potential experience and on education to be the same for men and women, this will result in the absence of a pure wage discrimination component in the decomposition as shown in equation (25). Instead the gender wage gap will be attributed to some combination of human capital differences and hierarchical segregation. Table 7 provides the coefficient estimates as well as the decomposition results associated with equation (25). Our findings indicate that the distributions of males and females are not equalized across job titles given that the coefficient of segregation, $\gamma$, is greater than 1. The highest percentage of the gender wage gap is attributed to hierarchical segregation, where 3.66 dollars of the 2.87 dollar wage gap is due to women being excluded from higher paying job titles. Moreover, -52.43 cents of the gender wage gap is attributed to worker characteristics. This is not surprising given that the negative sign implies that women have the advantage in human capital accumulation, thus were more qualified for promotion. The remaining wage difference is explained by the statistical correction factor, which adjusts for the difference in predicted average wages and sample mean wages, and the interaction effect.

Interestingly, the results obtained using the CPS data are consistent with what we learned from the single firm example. We find in both cases that if the researcher does not account for the non-discriminatory wage structure within job titles, the segregation effect is inflated by at least a factor of 2 . In both samples, the wage discrimination effect is estimated to be in favor of the male workers. As a result, we would incorrectly interpret these findings to suggest that women are paid more then their male counterparts with identical characteristics within the same job title. ${ }^{17}$ Furthermore, all the components of the wage gap have implausibly large magnitudes.

\footnotetext{
${ }^{17}$ This result is not surprising. If hierarchical segregation exists, then it is probably the case that women have higher education and experience levels, but are not being promoted. Thus in the absence of insider knowledge of the wage structure, the decomposition from equation (24) will incorrectly capture part of the segregation and endowment effect in the discrimination component.
} 
Because the CPS data are not firm-level, we do not have information on specific job titles which precludes a meaningful comparison between the BBJ inspired decomposition and a conventional decomposition. Some researchers use occupation codes to proxy job titles, however the choice and aggregation are arbitrary, making it difficult to proxy a hierarchical structure. Again, the BBJ approach finesses this issue as well as the issue of non-overlapping job titles and is able to identify the human capital effect apart from the segregation effect, which is not the case when using the conventional wage-level decomposition.

This exercise has allowed us to validate the use of the BBJ inspired decomposition to estimate the effect of job segregation on the gender wage gap as well as determine the direction and magnitude of the bias that can result when using nationally representative data where the wage structure is unknown. In general, if the wage structure is known to the extent that there is some knowledge that overt wage discrimination is nonexistent (i.e. union workers) we can constrain the model parameters and jointly maximize the male and female likelihood functions to obtain the segregation parameter and calculate the factors that contribute to the gender wage gap. If we do not have knowledge regarding the wage structure of the firms that the individuals belong to, then we at least have an idea of the direction of the bias.

\section{CONCLUSION}

This paper evaluates and extends existing methodologies used to estimate intrafirm segregation on the gender wage gap. In particular, we provide an empirical application of the BBJ theory of hierarchical discrimination using detailed payroll data from a single firm. These data provide an opportunity to examine how standard wage specifications integrated with a model of hierarchical segregation might perform in wage decompositions that seek to measure the contributions of endowments, pure wage discrimination, and segregation. 
The advantage of using the BBJ model is that it establishes the relationship between occupational segregation and wage discrimination such that the effects of occupational segregation can be identified without having to commit to a particular job title aggregation. In our case because the job titles are quite detailed, the conventional decompositions will result in the empty cell problem because of a lack of complete overlap across job titles. There are job positions filled either solely by women (males) and thus dropped from the male (female) regressions. In a conventional decomposition with log wages and non overlapping occupational categories, the terms corresponding to the non overlapping occupational variables confound identification of the wage effects of characteristics, discrimination, and segregation. This problem is not resolved by converting the decompositions over to wage level gaps. When we extend the BBJ decomposition to allow for nonlinearities that arise from the assumed wage distribution and include an interaction term that frees the segregation effect from being dependent on the factors that contribute to wage discrimination, we are able to better identify the segregation effect and determine the direction of the bias that results from not knowing the wage structure.

This study finds that inferences about the role of pure wage discrimination (and job segregation) in determining gender wage gaps can be greatly distorted by the specification error that arises from imposing otherwise plausible models of gender wage gaps. We validate the use of the hierarchical discrimination methodology by applying our extension of the BBJ decomposition to CPS data. The results obtained using the CPS data are consistent with what we find from the grocery store data in that if the researcher does not account for the non-discriminatory wage structure within job titles, the segregation effect is hugely inflated and we misinterpret wage discrimination against men when there is no wage discrimination at all.

We hope our research brings to light issues that arise when interpreting wage decompositions in the usual setting in which the wage structure is unknown. Further 
research is necessary to find more flexible wage specifications in situations where the true wage structure of the firm is unknown by the researcher. We believe that most unionized (or even non-union) firm level data will not follow any conventional distribution, therefore a non-parametric route may be more informative. It is more difficult to substantiate a claim of discriminatory practices against a firm if prima facie evidence shows that they employ the same wage structure within a given job title irrespective of gender.

Our findings suggest that even though we believe that our data are better suited to evaluate the hierarchical model developed by BBJ and our extensions of the model, we remain cautious about our inferences. However we are able to provide a lower bound on the degree of bias that results when using household survey data. Further exploration with other wage distributions and other firm data is in order before drawing definitive conclusions about the usefulness and sensitivity of the hierarchical model. 


\section{REFERENCES}

Baldwin, M., Butler, R., and Johnson W.: A Hierarchical Theory of Occupational Segregation and Wage Discrimination. Econ Inq. 39(1), 94-110 (2001)

Bayard, K., Hellerstein, J, Neumark, D., and Troske K.: New Evidence on Sex Segregation and Sex Differences in Wages from Matched Employee-Employer Data. J Labor Econ. 21(4), 887-922 (2003)

Bergmann, B.: Does the Market For Women's Labor Need Fixing? J Econ Perspect. 3(1), 43-60 (1989)

Blau, F., and Ferber, M.: Career Plans and Expectations of Young Women and Men: The Earnings Gap and Labor Force Participation. J Human Res. 26(4), 581-607 (1991)

Costa, D.: From Mill Town to Board Room: The Rise of Women's Paid Labor. J Econ Perspect. 14(4):101-122 (2000).

Costco Class Action Discrimination Lawsuit: Women Sue Costco. http://genderclassactionagainstcostco.com (accessed February 19, 2008)

Jeanine P., "Costco Class Action Suit Blocked," The Street, September 16, 2011, Accessed September 1, 2012 http://www.thestreet.com/story/11251458/1/costcoclass-action-suit-blocked.html.

Fuchs, V.: Women's Quest for Economic Equality. Cambridge: Harvard University Press (1988)

Gardeazabal, J. and Ugidos A.: More on Identification in Detailed Wage Decompositions. Rev Econ Statist. 86(4), 1034-1036 (2004). 
Gelbach, J.: Identified Heterogeneity in Detailed Wage Decompositions. Unpublished, Department of Economics, University of Arizona (2002).

Goldin, C.: Understanding the Gender Gap: An Economic History of American Women. New York: Oxford University Press (1990).

Johnson, G. and Solon,G.: Estimates of the Direct Effects of Comparable Worth Policy. Amer Econ Rev. 76(5),1117-1125 (1986)

Jones, F.L.: On Decomposing the Wage Gap: A Critical comment on Blinder's Method. J Human Res. 18(1), 126-130 (1983)

MacPherson, D. and Hirsch, B.: Wages and Gender Composition: Why Do Women's Jobs Pay Less? J Lab Econ. 13(3), 426-471 (1995)

Malkiel, B. and Malkiel J.: Male-Female Pay Differentials in Professional Employment. Amer Econ Rev. 63(4), 693-705 (1973)

National Union of Public and General Employees. Green light for massive class-action lawsuit against Wal-Mart. http://www.nupge.ca/news_2007/n09fe07b.htm (accessed February 9, 2007)

Andrew M., "Female Wal-Mart Employees File New Bias Case," The New York Times, October 27, 2011, Accessed September 1, 2012, http://www.nytimes.com/2011/10/28/business/women-file-new-class-actionbias-case-against-wal-mart.html

Oaxaca, R.: Male-Female Wage Differentials in Urban Labor Markets. Int Econ Rev. 14(3), 693-709 (1973)

Oaxaca, R. and Ransom, M.: Identification in Detailed Wage Decompositions. Rev Econ Statist. 81(1), 154-157 (1999) 
Oaxaca, R. and Ransom, M.: Using Econometric Models for Intrafirm Equity Salary Adjustments. J Econ Inequal. 1(3), 221-249 (2003)

Olson, C. and Becker, B.: Sex Discrimination in the Promotion Process. Review Ind Lab Relat Rev. 36(4), 624-641 (1983)

Polachek, S.: Occupational Self Selection: A Human Capital Approach to Sex Differences in Occupational Structure. Rev Econ Statist. 63(1), 60-69 (1981)

Polachek, S.: Occupational Segregation and the Gender Wage Gap. Population Res Pol Rev. 1(6), 47-67 (1987)

Ransom, M. and Oaxaca, R.: Intrafirm Mobility and Sex Differences in Pay. Ind Lab Relat Rev. 58(2), 219-237 (2005)

Sarnikar, S., Sorensen, T., and Oaxaca, R.: Do You Receive a Lighter Prison Sentence Because You Are a Woman? An Economic Analysis of Federal Criminal Sentencing Guidelines. Working Paper IZA DP No. 2870 (2010).

Sorensen, E.: Measuring the Pay Disparity Between Typically Female Occupations and Other Jobs: A Bivariate Selectivity Approach. Ind Lab Relat Rev. 42(4), 624-639 (1989)

Sorensen, E.: The Crowding Hypothesis and Comparable Worth. J Human Res. 25(1), 55-89 (1990)

Walmart Class- Case Developments. http://www.walmartclass.com/public_home.html (accessed February 19, 2008).

Yun, M.: A Simple Solution to the Identification Problem in Detailed Wage Decompositions. Econ. Inquiry. 43(4), 766-772 (2005) 


\begin{tabular}{|c|c|c|}
\hline $\mathrm{T}$ & ble 1 & \\
\hline Characterisitcs & f Job Holder & s, 1981 \\
\hline Job Title & Female & Male \\
\hline & $\mathbf{M}_{\mathbf{c}}$ & \\
\hline Assistant Manager & & \\
\hline Observations & 3 & 50 \\
\hline Age & 43.43 & 33.65 \\
\hline Tenure & 7.70 & 11.32 \\
\hline Hourly Wage & - & - \\
\hline Weekly Salary & 541 & 546.1915 \\
\hline Earnings & 26744 & 26861.56 \\
\hline Courtesy Clerk & & \\
\hline Observations & 73 & 163 \\
\hline Age & 20.12 & 19.14 \\
\hline Tenure & 0.88 & 0.90 \\
\hline Hourly Wage & 3.30 & 3.14 \\
\hline Weekly Salary & - & - \\
\hline Earnings & 3315.74 & 2866.637 \\
\hline Food Clerk & & \\
\hline Observations & 540 & 446 \\
\hline Age & 38.14 & 26.94 \\
\hline Tenure & 6.31 & 5.18 \\
\hline Hourly Wage & 8.42 & 8.23 \\
\hline Weekly Salary & - & - \\
\hline Earnings & 15077.98 & 15259.61 \\
\hline Meat Cutter & & \\
\hline Observations & 5 & 152 \\
\hline Age & 35.62 & 40.64 \\
\hline Tenure & 1.74 & 6.24 \\
\hline Hourly Wage & 9.55 & 10.47 \\
\hline Weekly Salary & - & - \\
\hline Earnings & 13171.02 & 22372.79 \\
\hline Meat Manager & & \\
\hline Observations & 0 & 55 \\
\hline Age & - & 41.11 \\
\hline Tenure & - & 12.39 \\
\hline Hourly Wage & - & 10.80 \\
\hline Weekly Salary & - & - \\
\hline Earnings & - & 28370.97 \\
\hline Meat Wrapper & & \\
\hline Observations & 74 & 0 \\
\hline Age & 42.91 & - \\
\hline Tenure & 8.46 & - \\
\hline Hourly Wage & 9.53 & - \\
\hline Weekly Salary & - & - \\
\hline Earnings & 17940.52 & - \\
\hline Night Manager & & \\
\hline Observations & 3 & 48 \\
\hline Age & 44.40 & 29.43 \\
\hline Tenure & 9.86 & 6.16 \\
\hline Hourly Wage & 8.75 & 9.05 \\
\hline Weekly Salary & - & - \\
\hline Earnings & 18699.25 & 18745 \\
\hline Other & & \\
\hline Observations & 8 & 10 \\
\hline Age & 42.26 & 27.03 \\
\hline Tenure & 7.47 & 1.39 \\
\hline Hourly Wage & 6.47 & 6.25 \\
\hline Weekly Salary & - & - \\
\hline Earnings & 10728.4 & 10118.09 \\
\hline Produce Clerk & & \\
\hline Observations & 11 & 97 \\
\hline Age & 25.91 & 28.09 \\
\hline Tenure & 2.48 & 6.14 \\
\hline Hourly Wage & 7.65 & 8.28 \\
\hline Weekly Salary & - & - \\
\hline Earnings & 12155.63 & 15895.88 \\
\hline Produce Manager & & \\
\hline Observations & 0 & 53 \\
\hline Age & - & 37.02 \\
\hline Tenure & - & 14.98 \\
\hline Hourly Wage & - & 9.25 \\
\hline Weekly Salary & - & - \\
\hline Earnings & - & 23608.24 \\
\hline Relief Manager & & \\
\hline Observations & 3 & 53 \\
\hline Age & 25.62 & 28.75 \\
\hline Tenure & 8.69 & 6.50 \\
\hline Hourly Wage & - & - \\
\hline Weekly Salary & 513 & 518.3617 \\
\hline Earnings & 22948.71 & 24001.46 \\
\hline Store Manager & & \\
\hline Observations & 0 & 56 \\
\hline Age & - & 38.87 \\
\hline Tenure & - & 15.28 \\
\hline Hourly Wage & - & - \\
\hline Weekly Salary & - & 604.8571 \\
\hline Earnings & - & 32663.17 \\
\hline Variety Clerk & & \\
\hline Observations & 66 & 0 \\
\hline Age & 34.05 & - \\
\hline Tenure & 6.35 & - \\
\hline Hourly Wage & 6.98 & - \\
\hline Weekly Salary & - & - \\
\hline Earnings & 12108.52 & - \\
\hline
\end{tabular}


Table 2: Distribution of Men and Women across Job Hierarchy, 1981

\begin{tabular}{|c|c|c|c|c|c|}
\hline Hierarchy Level & Percentage Male & Percentage Female & Fraction of all Men & Fraction of all Women & Relative Proportion \\
\hline h1 & 52.6 & 47.4 & 0.138 & 0.185 & 1.345 \\
\hline h2 & 52.5 & 47.5 & 0.596 & 0.803 & 1.348 \\
\hline h3 & 98.1 & 1.9 & 0.132 & 0.004 & 0.029 \\
\hline h4 & 94.6 & 5.4 & 0.045 & 0.004 & 0.084 \\
\hline h5 & 94.3 & 5.7 & 0.042 & 0.004 & 0.090 \\
\hline h6 & 100 & 0 & 0.047 & 0.000 & 0.000 \\
\hline \multicolumn{6}{|c|}{$\begin{array}{l}\text { h1 = Courtesy Clerk and Meat Wrapper } \\
\text { h2 = Variety Clerk, Food Clerk, Produce Clerk, Meat Cutter, and Other } \\
\text { h3 = Night Crew Chief, Produce Manager, and Meat Manager } \\
\text { h4 = Relief Manager } \\
\text { h5 = Assistant Manager } \\
\text { h6 = Store Manager }\end{array}$} \\
\hline
\end{tabular}




\begin{tabular}{|c|c|c|c|c|}
\hline Variable & $\mathbf{I}$ & II & III & IV \\
\hline \multirow[t]{2}{*}{ constant } & 2.075 & 0.223 & 0.632 & 1.357 \\
\hline & {$[0.011]^{* * *}$} & {$[0.051]^{* * *}$} & {$[0.033]^{* * *}$} & {$[0.012]^{* * *}$} \\
\hline \multirow[t]{2}{*}{ female } & -0.044 & -0.134 & -0.067 & -0.019 \\
\hline & {$[0.018]^{* *}$} & {$[0.012]^{* * *}$} & {$[0.009]^{* * *}$} & {$[0.011]^{*}$} \\
\hline \multirow[t]{2}{*}{ tenure } & - & 0.047 & 0.028 & - \\
\hline & & {$[0.003]^{* * *}$} & {$[0.002]^{* * *}$} & \\
\hline \multirow[t]{2}{*}{ ten 2} & - & -0.001 & -0.001 & - \\
\hline & & {$[0.000]^{* * *}$} & {$[0.000]^{* * *}$} & \\
\hline \multirow[t]{2}{*}{ age } & - & 0.094 & 0.044 & - \\
\hline & & {$[0.003]^{* * *}$} & {$[0.002]^{* * *}$} & \\
\hline \multirow[t]{2}{*}{ age 2} & - & -0.001 & -0.001 & - \\
\hline & & {$[0.000]^{* * *}$} & {$[0.000]^{* * *}$} & \\
\hline \multirow[t]{2}{*}{ food_clerk81 } & - & - & 0.585 & 0.764 \\
\hline & & & {$[0.012]^{* * *}$} & {$[0.014]^{* * *}$} \\
\hline \multirow[t]{2}{*}{ night_stocking_manager81 } & 一 & - & 0.628 & 0.845 \\
\hline & & & {$[0.025]^{* * *}$} & {$[0.031]^{* * *}$} \\
\hline \multirow[t]{2}{*}{ produce_clerk 81} & - & - & 0.579 & 0.738 \\
\hline & & & {$[0.018]^{* * *}$} & {$[0.023]^{* * *}$} \\
\hline \multirow[t]{2}{*}{ meat_manager81 } & 一 & - & 0.665 & 1.023 \\
\hline & & & {$[0.025]^{* * *}$} & {$[0.030]^{* * *}$} \\
\hline \multirow[t]{2}{*}{ meat_cutter81 } & 一 & - & 0.734 & 0.989 \\
\hline & & & {$[0.018]^{* * *}$} & {$[0.020]^{* * *}$} \\
\hline \multirow[t]{2}{*}{ meat_wrapper81 } & - & - & 0.682 & 0.917 \\
\hline & & & {$[0.023]^{* * *}$} & {$[0.028]^{* * *}$} \\
\hline \multirow{2}{*}{ variety_clerk81 } & - & - & 0.424 & 0.598 \\
\hline & & & {$[0.023]^{* * *}$} & {$[0.029]^{* * *}$} \\
\hline \multirow[t]{2}{*}{ other81 } & - & - & 0.327 & 0.467 \\
\hline & & & {$[0.038]^{* * *}$} & {$[0.049]^{* * *}$} \\
\hline \multirow[t]{2}{*}{ store_manager81 } & - & - & 0.971 & 1.328 \\
\hline & & & {$[0.025]^{* * *}$} & {$[0.030]^{* * *}$} \\
\hline \multirow[t]{2}{*}{ asst_manager81 } & - & - & 0.828 & 1.14 \\
\hline & & & {$[0.025]^{* * *}$} & {$[0.030]^{* * *}$} \\
\hline \multirow[t]{2}{*}{ relief_manager81 } & 一 & - & 0.81 & 1.025 \\
\hline & & & {$[0.024]^{* * *}$} & {$[0.030]^{* * *}$} \\
\hline courtesy_clerk & \multicolumn{4}{|c|}{ left out reference group } \\
\hline$\overline{\mathrm{N}}$ & 1968 & 1968 & 1968 & 1968 \\
\hline R-Squared & 0.0031 & 0.5635 & 0.8333 & 0.7214 \\
\hline \multicolumn{5}{|c|}{$\begin{array}{l}\text { Standard errors in brackets } \\
* \text { significant at } 10 \% ; * * \text { significant at } 5 \% ; * * * \text { significant at } 1 \%\end{array}$} \\
\hline
\end{tabular}


Table 4: Homogenous Lognormal Regression and Decomposition

\begin{tabular}{|c|c|c|c|c|c|}
\hline$\mu$ & $=$ & 2.08 & Decomposition & Wage Difference & Percent Difference \\
\hline & & {$[0.110]^{* * *}$} & & & \\
\hline$\sigma$ & $=$ & $\begin{array}{c}0.3783 \\
{[0.0058]^{* * *}}\end{array}$ & Segregation & 0.7081 & 1.0674 \\
\hline$\gamma$ & $=$ & $\begin{array}{c}1.0945 \\
{[0.0088]^{* * *}}\end{array}$ & Non-linear & -0.0447 & -0.0674 \\
\hline $\mathrm{N}$ & $=$ & 1968 & Total & 0.6628 & 1 \\
\hline
\end{tabular}


Table 5: Heterogenous Lognormal Regression-No Discrimination

\begin{tabular}{|c|c|c|}
\hline \multicolumn{3}{|c|}{ Grocery Store Sample } \\
\hline \multirow{3}{*}{ constant } & \multicolumn{2}{|c|}{ Pooled Men and Women } \\
\hline & & 0.1388 \\
\hline & & {$[0.0513]^{* * *}$} \\
\hline \multirow[t]{2}{*}{ age } & & 0.0969 \\
\hline & & {$[0.0032]^{* * *}$} \\
\hline \multirow[t]{2}{*}{ age-squared } & & -0.0011 \\
\hline & & {$[0.0000]^{* * *}$} \\
\hline \multirow[t]{2}{*}{ tenure } & & 0.0469 \\
\hline & & {$[0.0029]^{* * *}$} \\
\hline \multirow[t]{2}{*}{$\operatorname{ten} 2$} & & -0.0015 \\
\hline & & {$[0.0001]^{* * *}$} \\
\hline \multirow[t]{2}{*}{$\sigma^{2}$} & & 0.2582 \\
\hline & & {$[0.0042] * * *$} \\
\hline \multirow[t]{2}{*}{$\gamma$} & & 1.0794 \\
\hline & & {$[0.0064]^{* * *}$} \\
\hline $\mathrm{N}$ & & 1968 \\
\hline \multicolumn{3}{|c|}{ based off of joint estimation of the male and female likelihood functions } \\
\hline Decomposition & Wage Difference & Percent Difference \\
\hline Endowment & -0.9470 & -1.4289 \\
\hline Discrimination & 0.0000 & 0.0000 \\
\hline Segregation & 1.4032 & 2.1172 \\
\hline Non-linear & -0.0042 & -0.0063 \\
\hline Interaction & 0.2107 & 0.3179 \\
\hline Total & 0.6628 & 1 \\
\hline
\end{tabular}




\begin{tabular}{|c|c|c|}
\hline & \multicolumn{2}{|c|}{ Hourly Wage } \\
\hline & $\underline{\text { Male }}$ & Female \\
\hline \multirow[t]{2}{*}{ age } & $\overline{0.019}$ & 0.016 \\
\hline & {$[0.002]^{* * *}$} & {$[0.003]^{* * *}$} \\
\hline \multirow[t]{2}{*}{ age 2} & 0 & 0 \\
\hline & {$[0.000]^{* * *}$} & {$[0.000]^{* * *}$} \\
\hline \multirow[t]{2}{*}{ tenure } & 0.016 & 0.025 \\
\hline & {$[0.002]^{* * *}$} & {$[0.002]^{* * *}$} \\
\hline \multirow[t]{2}{*}{ ten 2} & 0 & -0.001 \\
\hline & {$[0.000]^{* * *}$} & {$[0.000]^{* * *}$} \\
\hline \multirow[t]{2}{*}{ store_manager81 } & 1.349 & 0 \\
\hline & {$[0.022]^{* * *}$} & {$[0.000]$} \\
\hline \multirow[t]{2}{*}{ asst_manager81 } & 1.174 & 1.098 \\
\hline & {$[0.022]^{* * *}$} & {$[0.066]^{* * *}$} \\
\hline \multirow[t]{2}{*}{ relief_manager81 } & 1.101 & 1.012 \\
\hline & {$[0.020]^{* * *}$} & {$[0.065]^{* * *}$} \\
\hline \multirow[t]{2}{*}{ food_clerk81 } & 0.843 & 0.777 \\
\hline & {$[0.013]^{* * *}$} & {$[0.018]^{* * *}$} \\
\hline \multirow[t]{2}{*}{ night_stocking_manager81 } & 0.927 & 0.741 \\
\hline & {$[0.021]^{* * *}$} & {$[0.066]^{* * *}$} \\
\hline \multirow[t]{2}{*}{ produce_manager81 } & 0.889 & 0 \\
\hline & {$[0.022]^{* * *}$} & {$[0.000]$} \\
\hline \multirow[t]{2}{*}{ produce_clerk81 } & 0.847 & 0.749 \\
\hline & {$[0.016]^{* * *}$} & {$[0.036]^{* * *}$} \\
\hline \multirow[t]{2}{*}{ meat_manager81 } & 1.038 & 0 \\
\hline & {$[0.022]^{* * *}$} & {$[0.000]$} \\
\hline \multirow[t]{2}{*}{ meat_cutter81 } & 1.05 & 0.952 \\
\hline & {$[0.017]^{* * *}$} & {$[0.052]^{* * *}$} \\
\hline \multirow[t]{2}{*}{ meat_wrapper81 } & 0 & 0.891 \\
\hline & {$[0.000]$} & {$[0.022]^{* * *}$} \\
\hline \multirow[t]{2}{*}{ variety_clerk81 } & 0 & 0.594 \\
\hline & {$[0.000]$} & {$[0.021]^{* * *}$} \\
\hline \multirow[t]{2}{*}{ other81 } & 0.572 & 0.496 \\
\hline & {$[0.037]^{* * *}$} & {$[0.042]^{* * *}$} \\
\hline \multirow[t]{2}{*}{ Constant } & 0.863 & 0.934 \\
\hline & {$[0.033]^{* * *}$} & {$[0.038]^{* * *}$} \\
\hline$\overline{\mathrm{N}}$ & 1182 & $7 \overline{786}$ \\
\hline R-squared & 0.93 & 0.88 \\
\hline $\begin{array}{l}\text { Standard errors in bracke } \\
* \text { significant at } 10 \% ; * *\end{array}$ & ant at $5 \%$; & nificant at $1 \%$ \\
\hline
\end{tabular}


Table 7: Heterogenous Lognormal Regression-No Discrimination

\begin{tabular}{|c|c|c|}
\hline \multicolumn{3}{|c|}{ CPS Sample } \\
\hline & \multicolumn{2}{|c|}{ Pooled Men and Women } \\
\hline constant & \multicolumn{2}{|r|}{1.6531} \\
\hline Education & \multicolumn{2}{|r|}{0.0833} \\
\hline Experience & \multicolumn{2}{|r|}{0.0272} \\
\hline Experience2 & \multicolumn{2}{|r|}{-0.0005} \\
\hline$\sigma^{2}$ & \multicolumn{2}{|r|}{0.4313} \\
\hline$\gamma$ & \multicolumn{2}{|r|}{1.0430} \\
\hline & \multicolumn{2}{|r|}{269} \\
\hline \multicolumn{3}{|c|}{ based off of joint estimation of the male and female likelihood functions } \\
\hline Decomposition & Wage Difference & Percent Difference \\
\hline Endowment & -0.5253 & -0.1830 \\
\hline Discrimination & 0 & 0 \\
\hline Segregation & 3.6595 & 1.2748 \\
\hline Non-linear & -0.4057 & -0.1413 \\
\hline Interaction & 0.1423 & 0.0496 \\
\hline Total & 2.870774 & 1 \\
\hline
\end{tabular}




\section{Appendix: The Gamma Distribution}

In this appendix present the gender wage decompositions in the hierarchical model when wages follow the gamma distribution. The male wage density without covariates is given by

$$
g_{m}(w)=\frac{w^{p-1} \exp \left(\frac{-w}{\beta}\right)}{(\beta)^{p} \Gamma(p)},
$$

where wages represent a continuum of jobs. As in the case of the log normal distribution, in this example from the class of exponential distributions the female wage density $g_{f}(w)$ is obtained from the discriminatory sorting function $s(w)$ and the male wage density $g_{m}(w)$ where

$$
s(w)=\left[\left(\frac{\lambda+\beta}{\lambda}\right)^{p} * \exp \left(\frac{w}{\lambda}\right)\right] .
$$

Consequently, the female wage density $g_{f}(w)$ follows the gamma distribution: 


$$
\begin{aligned}
g_{f}(w)= & s(w) * g_{m}(w) \\
= & {\left[\left(\frac{\lambda+\beta}{\lambda}\right)^{p} * \exp \left(\frac{w}{\lambda}\right)\right] *\left[\frac{w^{p-1} \exp \left(\frac{-w}{\beta}\right)}{\beta \Gamma(p)}\right] } \\
& =\frac{w^{p-1} \exp \left[\frac{-w}{\left(\frac{\beta \lambda}{\beta+\lambda}\right)}\right]}{\left(\frac{\beta \lambda}{\beta+\lambda}\right)^{p} \Gamma(p)},
\end{aligned}
$$

where $\lambda$ is a parameter that represents the rate of decline of the proportion of females relative to the proportion of males as one moves up the job hierarchy, i.e. $\frac{\partial \ln [s(w)]}{\partial w}=$ $\frac{1}{\lambda}$. The parameter $\lambda$ is indicative (negatively) of the degree of job title segregation since $\frac{\partial^{2} \ln [s(w)]}{\partial w \partial \lambda}=\frac{-1}{\lambda^{2}}<0$ and $\lim _{\lambda \rightarrow \infty} g_{f}(w)=g_{m}(w)$. Conceptually, it is preferable to introduce the normalization $\psi=\lambda^{-1} \geq 0$ so that the absence of segregation implies $\psi=0$.

We first consider the special case in which wages within each job title are fixed and workers are homogenous. With no differences in characteristics other than sex, and wages being equalized within each job category, the decomposition reduces to a segregation term. The expected wage difference between males and females is given by

$$
\begin{aligned}
E\left(w_{m}\right)-E\left(w_{f}\right) & =(p \beta)-(p)\left(\frac{\beta}{\psi \beta+1}\right) \\
& =(p \beta)\left(\frac{\psi \beta}{\psi \beta+1}\right) .
\end{aligned}
$$

One would operationalize the model by using the MLE parameter estimates obtained from the combined samples of males and females, and by taking account of deviations 
between sample means and predicted sample means:

$$
\begin{aligned}
\bar{w}_{m} & =\hat{p} \hat{\beta}+\hat{\theta}_{m} \\
\bar{w}_{f} & =(\hat{p})\left(\frac{\hat{\beta}}{\hat{\psi} \hat{\beta}+1}\right)+\hat{\theta}_{f} \\
\bar{w}_{m}-\bar{w}_{f} & =(\hat{p} \hat{\beta})\left(\frac{\hat{\psi} \hat{\beta}}{\hat{\psi} \hat{\beta}+1}\right)+\left(\hat{\theta}_{m}-\hat{\theta}_{f}\right)
\end{aligned}
$$

where $\widehat{\theta}_{m}$ and $\widehat{\theta}_{f}$ are remainder terms that equate the means of the predicted wages for males and females to their sample means. The first term in (4) is the empirical estimate of the gender wage gap effects of segregation, and the second term captures the sample mean wage difference due to gender differences in the deviation between sample mean wages and predicted mean wages.

In order to accommodate worker heterogeneity, we follow BBJ in replacing the scale parameter $\beta$ by a function. The density functions are accordingly expressed as

$$
\begin{array}{r}
g_{m}(w)=\frac{w^{p-1} \exp \left(\frac{-w}{\beta_{m}}\right)}{\left(\beta_{m}\right)^{p} \Gamma(p)} \\
w^{p-1} \exp \left[\frac{-w}{\left(\frac{\beta_{f}}{\psi \beta_{f}+1}\right)}\right] \\
\left(\frac{\beta_{f}}{\psi \beta_{f}+1}\right)^{p} \Gamma(p)
\end{array}
$$

Conditioning on worker characteristics $(x)$ introduces additional parameters $(\delta)$, where $\beta_{m}=\exp \left(x_{m} \delta_{m}\right)$ and $\beta_{f}=\exp \left(x_{f} \delta_{f}\right)^{1}$. With worker heterogeneity the presence of wage discrimination implies that female wage rates within each job title $z$ are a fraction $(\phi)$ of the wage rates the females would face if their characteristics were valued

\footnotetext{
${ }^{1}$ We depart from BBJ by specifying the scale parameter functions as exponential functions of covariates rather than as linear functions. We find that using exponential link functions as opposed to linear link functions has better convergence properties for our work.
} 
at the male returns. Worker heterogeneity and wage discrimination imply

$$
E(z)=(\phi)(p)\left(\frac{\beta_{f}^{0}}{\psi \beta_{f}^{0}+1}\right)
$$

where $\beta_{f}^{0}=\exp \left(x_{f} \delta_{m}\right)$. The female wage density (6) implies

$$
E(z)=(p)\left(\frac{\beta_{f}}{\psi \beta_{f}+1}\right)
$$

Upon equating (7) to (8) and simplifying terms, we can solve for $\phi$ :

$$
\phi=\left(\frac{\beta_{f}}{\psi \beta_{f}+1}\right)\left(\frac{\psi \beta_{f}^{0}+1}{\beta_{f}^{0}}\right) .
$$

Clearly in the absence of wage discrimination, $\delta_{m}-\delta_{f}=0 \Rightarrow \beta_{f}=\beta_{f}^{0} \Rightarrow \phi=1$. One can maximize the likelihood function for the combined sample of males and females with respect to the parameters $\delta_{m}, \delta_{f}, \psi$, and $p$.

The expected wage gap between a representative male and a representative female at the respective sample mean characteristics can be written as

$$
E\left(w_{m} \mid \bar{x}_{m}\right)-E\left(w_{f} \mid \bar{x}_{f}\right)=(p)\left(\bar{\beta}_{m}\right)-(p)\left(\frac{\bar{\beta}_{f}}{\psi \bar{\beta}_{f}+1}\right)
$$

where $\bar{\beta}_{m}=\exp \left(\bar{x}_{m} \delta_{m}\right)$ and $\bar{\beta}_{f}=\exp \left(\bar{x}_{f} \delta_{f}\right)$. After some algebraic manipulation, the expected wage gap can be decomposed according to

$$
E\left(w_{m} \mid \bar{x}_{m}\right)-E\left(w_{f} \mid \bar{x}_{f}\right)=(p)\left(\bar{\beta}_{m}-\bar{\beta}_{f}^{0}\right)+(p)\left(\bar{\beta}_{f}^{0}-\bar{\beta}_{f}\right)+(p)\left(\bar{\beta}_{f}\right)\left(\frac{\psi \bar{\beta}_{f}}{\psi \bar{\beta}_{f}+1}\right)
$$

where $\bar{\beta}_{f}^{0}=\exp \left(\bar{x}_{f} \delta_{m}\right)$. The three RHS terms in (10) respectively correspond to the individual characteristics, wage discrimination, and segregation effects.

One might take issue with the fact that the discrimination measure depends on the characteristics of the female sample and the segregation measure depends on the extent of discrimination against women as well as on the characteristics of the female sample. Analogous to the interaction terms used in decompositions to address this 
issue, we add and subtract the terms $(p)\left(\bar{\beta}_{m}-\bar{\beta}_{m f}\right)$ and $(p)\left(\bar{\beta}_{m}\right)\left(\frac{\psi \bar{\beta}_{m}}{\psi \bar{\beta}_{m}+1}\right)$, where $\bar{\beta}_{m f}=\exp \left(\bar{x}_{m} \delta_{f}\right)$. The resulting decomposition is given by

$$
\begin{aligned}
E\left(w_{m} \mid \bar{x}_{m}\right)-E\left(w_{f} \mid \bar{x}_{f}\right)= & (p)\left(\bar{\beta}_{m}-\bar{\beta}_{f}^{0}\right)+(p)\left(\bar{\beta}_{m}-\bar{\beta}_{m f}\right)+(p)\left(\bar{\beta}_{m}\right)\left(\frac{\psi \bar{\beta}_{m}}{\psi \bar{\beta}_{m}+1}\right) \\
& +\rho\left\{\left[\left(\bar{\beta}_{f}^{0}-\bar{\beta}_{f}\right)-\left(\bar{\beta}_{m}-\bar{\beta}_{m f}\right)\right]\right. \\
& \left.+(\psi)\left[\left(\frac{\left(\bar{\beta}_{f}\right)^{2}}{\psi \bar{\beta}_{f}+1}\right)-\left(\frac{\left(\bar{\beta}_{m}\right)^{2}}{\psi \bar{\beta}_{m}+1}\right)\right]\right\} .
\end{aligned}
$$

The first three terms in (11) correspond to the individual characteristics, wage discrimination, and segregation effects, while the fourth term reflects the combination of differences in characteristics and parameters.

Since the decomposition described by (11) is evaluated at the sample mean characteristics, we note that wage level decompositions based on the gamma distribution do not in general correspond to the difference in the average of individual conditional mean wages. Consequently, our extension of the BBJ decomposition in this case involves expressions for the sample means of the estimated individual decomposition terms. In order to simplify the decomposition expression, we introduce the following notation:

$$
\begin{aligned}
& \hat{w}_{m}=N_{m}^{-1} \sum_{i=1}^{N_{m}} \hat{w}_{m_{i}}, \quad \hat{w}_{m_{i}}=\hat{p} \hat{\beta}_{m i}, \hat{\beta}_{m i}=\exp \left(x_{m i} \hat{\delta}_{m}\right), \\
& \hat{w}_{f}=N_{f}^{-1} \sum_{i=1}^{N_{f}} \hat{w}_{f_{i}}, \quad \hat{w}_{f_{i}}=\hat{p}\left(\frac{\hat{\beta}_{f i}}{\hat{\psi}_{\hat{\beta}} \hat{\beta}_{f i}+1}\right), \hat{\beta}_{f i}=\exp \left(x_{f i} \hat{\delta}_{f}\right), \\
& \hat{w}_{f}^{0}=N_{f}^{-1} \sum_{i=1}^{N_{f}} \hat{w}_{f_{i}}^{0}, \quad \hat{w}_{f_{i}}^{0}=\hat{p} \hat{\beta}_{f i}^{0}, \hat{\beta}_{f i}^{0}=\exp \left(x_{f i} \hat{\delta}_{m}\right), \\
& \hat{w}_{m f}=N_{m}^{-1} \sum_{i=1}^{N_{m}} \hat{w}_{m f_{i}}, \quad \hat{w}_{m f_{i}}=\hat{p} \hat{\beta}_{m f i}, \hat{\beta}_{m f i}=\exp \left(x_{m i} \hat{\delta}_{f}\right), \\
& \hat{w}_{\psi m}=N_{m}^{-1} \sum_{i=1}^{N_{m}} \hat{w}_{\psi m_{i}}, \quad \hat{w}_{\psi m_{i}}=\hat{p} \hat{\psi}\left(\frac{\left(\hat{\beta}_{m i}\right)^{2}}{\hat{\psi} \hat{\beta}_{m i}+1}\right),
\end{aligned}
$$

Again we let $\widehat{\theta}_{m}=\bar{w}_{m}-\hat{w}_{m}$ and $\widehat{\theta}_{f}=\bar{w}_{f}-\hat{w}_{f}$ be the remainder terms that equate 
the means of the predicted wages for males and females to their sample means. Our decomposition of the sample mean difference in wage levels is compactly expressed as

$$
\begin{aligned}
\bar{w}_{m}-\bar{w}_{f}= & \left(\hat{w}_{m}-\hat{w}_{f}^{0}\right)+\left(\hat{w}_{m}-\hat{w}_{m f}\right)+\left(\hat{w}_{\psi m}\right)+\left(\widehat{\theta}_{m}-\widehat{\theta}_{f}\right) \\
+ & \left(\hat{w}_{f}^{0}-\hat{w}_{m}+\hat{w}_{m f}-\hat{w}_{\psi m}-\hat{w}_{f}\right) .
\end{aligned}
$$

The first four terms on the RHS of (12) respectively correspond to endowment effects, wage discrimination, segregation effects, and the effects gender differences between sample mean wages and predicted mean wages. The fifth term residually reflects the interaction effects between endowments, discrimination, and segregation.

In the absence of pure wage discrimination, such as in the presence of gender neutral union wage contracts, one would impose the restriction $\delta_{m}=\delta_{f}=\delta$ in the likelihood function. Accordingly the decomposition simplifies to

$$
\begin{aligned}
\bar{w}_{m}-\bar{w}_{f}= & \left(\tilde{w}_{m}-\tilde{w}_{f}^{0}\right)+\left(\tilde{w}_{\psi m}\right)+\left(\tilde{\theta}_{m}-\tilde{\theta}_{f}\right) \\
+\left(\tilde{w}_{f}^{0}-\tilde{w}_{\psi m}-\tilde{w}_{f}\right) &
\end{aligned}
$$

where

$$
\begin{gathered}
\tilde{w}_{m}=N_{m}^{-1} \sum_{i=1}^{N_{m}} \tilde{w}_{m_{i}}, \quad \tilde{w}_{m_{i}}=\tilde{p} \tilde{\beta}_{m i}, \tilde{\beta}_{m i}=\exp \left(x_{m i} \hat{\delta}\right), \\
\tilde{w}_{f}=N_{f}^{-1} \sum_{i=1}^{N_{f}} \tilde{w}_{f_{i}}, \quad \tilde{w}_{f_{i}}=\tilde{p}\left(\frac{\tilde{\beta}_{f i}}{\tilde{\psi}_{\tilde{\beta}} \tilde{\beta}_{f i}+1}\right), \tilde{\beta}_{f i}=\exp \left(x_{f i} \hat{\delta}\right), \\
\tilde{w}_{f}^{0}=N_{f}^{-1} \sum_{i=1}^{N_{f}} \tilde{w}_{f_{i}}^{0}, \quad \hat{w}_{f_{i}}^{0}=\tilde{p} \tilde{\beta}_{f i}, \\
\tilde{w}_{\psi m}=N_{m}^{-1} \sum_{i=1}^{N_{m}} \tilde{w}_{\psi m_{i}}, \quad \tilde{w}_{\psi m_{i}}=\tilde{p} \tilde{\psi}\left(\frac{\left(\tilde{\beta}_{m i}\right)^{2}}{\tilde{\psi}_{\tilde{\beta}}+1}\right) \\
\tilde{\theta}_{m}=\bar{w}_{m}-\tilde{w}_{m} \text { and } \tilde{\theta}_{f}=\bar{w}_{f}-\tilde{w}_{f} .
\end{gathered}
$$

